\title{
From individuals to populations: How intraspecific competition shapes thermal reaction norms
}

Short title: Competition and thermal reaction norms

François Mallard ${ }^{1,2}$, Vincent Le Bourlot ${ }^{2}$, Christie Le Coeur ${ }^{1,3}$, Monique Avnaim ${ }^{1}$, Romain Péronnet ${ }^{1}$, David Claessen ${ }^{2 \#}$, Thomas Tully ${ }^{1 *}$.

1 - Institut d'écologie et des sciences de l'environnement de Paris

CNRS - UMR 7618, iEES Paris

Sorbonne Université

4 Place de Jussieu, 75005 Paris, France

2 - Institut de Biologie de l'ENS (IBENS)

Ecole Normale Supérieure,

46 rue d'Ulm, 75005 Paris, France

3 - Centre for Ecological and Evolutionary Synthesis (CEES), Department of Biosciences,

University of Oslo, P.O. Box 1066, Blindern, 0316 Oslo, Norway

*Correspondence author: thomas.tully@sorbonne-universite.fr

\#deceased July 2018

\section{Acknowledgements}

We thank two anonymous referees for their constructive comments that helped us to refine and clarify the manuscript.

We would like to pay tribute to David Claessen's memory. He left us in July 2018 and we are deeply saddened for the loss of an unforgettable friend and such a brilliant colleague. We are grateful for his contribution to this work.

\section{Authors' contributions}

FM, VLB, TT conceived the ideas and designed methodology. FM, VLB, CLC, MA, RP and TT collected the data. FM, VLB, TT analysed the data. FM and TT led the writing of the manuscript. VLB, DC and CLC participated to the writing of the manuscript.

All authors contributed critically to the drafts and gave approval for publication.

\section{Keywords}

Asymptotic size, body length, clonal variation, Collembola, demography, density-dependence, Folsomia candida, growth trajectory, growth rate, intraspecific competition, phenotypic plasticity, population dynamic, springtail, temperature size rule, thermal reaction norm.

DOI: $10.1111 / 1365-2435.13516$

https://besjournals.onlinelibrary.wiley.com/doi/abs/10.1111/1365-2435.13516

Mallard, F., Le Bourlot, V., Le Coeur, C., Avnaim, M., Péronnet, R., Claessen, D. et al. (2019). From individuals to populations: How intraspecific competition shapes thermal reaction norms. Functional Ecology. 10.1111/1365-2435.13516 


\section{Abstract}

1. Most ectotherms follow the temperature-size rule (TSR): in cold environments individuals grow slowly but reach a large asymptotic length. Intraspecific competition can induce plastic changes of growth rate and asymptotic length and competition may itself be modulated by temperature.

2. Our aim is to disentangle the joint effects of temperature and intraspecific competition on growth rate and asymptotic length.

3. We used two distinct clonal lineages of the Collembola Folsomia candida, to describe thermal reaction norms of growth rate, asymptotic length and reproduction over 6 temperatures between $6^{\circ} \mathrm{C}$ and $29^{\circ} \mathrm{C}$. In parallel, we measured the long-term size-structure and dynamics of springtail populations reared under the same temperatures to measure growth rates and asymptotic lengths in populations and to quantify the joint effects of competition and temperature on these traits.

4. We show that intraspecific competition modulates the temperature-size rule. In dense populations there is a direct negative effect of temperature on asymptotic length, but there is no temperature dependence of the growth rate, the dominant factor regulating growth being competition. The two lineages responded differently to the joint effects of temperature and competition on growth and asymptotic size and these genetic differences have marked effects on population structure along our temperature gradient.

5. Our results reinforce the idea that the TSR response of ectotherms can be modulated by biotic and abiotic stressors when studied in non-optimal laboratory experiments. Untangling complex interactions between environment and demography will help to understand how growth trajectories will respond to environmental change and how climate change may influence population size structure.

\section{Second language abstract}

1. La plupart des ectothermes suivent la règle de la taille-température (temperature-size rule, TSR) : dans les environnements froids, les individus grandissent lentement mais atteignent une grande longueur asymptotique. La compétition intraspécifique peut elle aussi affecter les taux de croissance et la longueur asymptotique et l'intensité de la compétition peut elle-même être modulée par la température.

2. Notre objectif ici est de démêler les effets conjoints de la température et de la compétition intraspécifique sur les taux de croissance et la longueur asymptotique.

3. Nous avons utilisé deux lignées clonales distinctes du Collembola Folsomia candida, pour décrire les normes de réaction thermique du taux de croissance, de la longueur asymptotique et de la reproduction sur six températures entre $6{ }^{\circ} \mathrm{C}$ et $29^{\circ} \mathrm{C}$. En parallèle, nous avons mesuré la structure en taille et la dynamique à long terme des populations de collemboles élevés aux même 6 températures pour mesurer les taux de croissance, les longueurs asymptotiques et l'intensité de la compétition dans les populations afin de pouvoir quantifier les effets conjoints de la compétition et de la température sur ces deux traits (croissance et taille).

4. Nous montrons que la compétition intraspécifique module la règle température-taille: dans les populations denses, il y a un effet négatif direct de la température sur la longueur asymptotique, mais il n'y a pas de dépendance à la température du taux de croissance, le facteur dominant régulant la croissance étant la compétition. Les deux lignées ont répondu différemment aux effets conjoints de la température et de la compétition sur la croissance et la taille asymptotique et ces différences génétiques ont des effets marqués sur la structure des populations le long de notre gradient de température.

5. Nos résultats renforcent l'idée que la réponse des ectothermes à la température peut être modulée par des facteurs de stress biotiques et abiotiques lorsqu'ils sont étudiés dans des expériences de laboratoire non optimales. Démêler les interactions complexes entre l'environnement (température) et la démographie (compétition) peut permettre de mieux comprendre comment les trajectoires de croissance peuvent répondra à des changements environnementaux et comment le changement climatique peut influencer la structure en taille des populations. 


\section{Introduction}

Temperature is a key abiotic factor that influences life history traits of ectothermic organisms through direct effects on physiological rates such as consumption, digestion, and metabolic or respiration rates (Angilletta, 2009; Atkinson, 1996; Edeline, Lacroix, Delire, Poulet, \& Legendre, 2013; Gillooly, Brown, West, Savage, \& Charnov, 2001). Thermal reaction norms of these traits have typically unimodal asymmetric shapes: the trait's performance first increases more or less linearly with increasing temperature, reaches a maximum at some optimal temperature and then decreases rapidly above this optimum (Kingsolver, 2009). Thermal reaction norms of asymptotic body length differ: most ectotherms follow the temperature-size rule (TSR), which states that adult body length decreases with increasing temperature despite an increase in average growth rate (Zuo, Moses, West, Hou, \& Brown, 2011; DeLong, 2012; Gardner, Peters, Kearney, Joseph, \& Heinsohn, 2011; Walters \& Hassall, 2006; Angilletta, 2009; Daufresne, Lengfellner, \& Sommer, 2009; Atkinson, 1994). The TSR is defined within thermally favourable conditions (Atkinson, 1994), which is often viewed as the thermal range between a minimal and an optimal temperature (Walczyńska, Kiełbasa, \& Sobczyk, 2016). Thus, most studies report measurements of reaction norms in optimal environments (including unlimited access to food resources) in order to avoid confounding indirect effects of temperature through densitydependent effects. Measurements are usually made on isolated individuals (Driessen, Ellers, \& Van Straalen, 2007; Ellers \& Driessen, 2011; Hoefnagel, de Vries, Jongejans, \& Verberk, 2018), small cohorts (Karan, Morin, Moreteau, \& David, 1998; Liefting, Hoffmann, \& Ellers, 2009; Karan et al., 1998; Liefting et al., 2009; Ghosh, Testa, \& Shingleton, 2013; Hoefnagel \& Verberk, 2015) or growing populations with reduced density-dependence effects reared in the laboratory (Walczyńska et al., 2016).

Although these laboratory experiments can tell us a lot about how environmental conditions alter individual phenotypes, their applicability to the way a population or a community responds to environmental change may be limited. Indeed, temperature affects not only the physiology of each individual but also the state of the population itself (in terms of abundance and structure). This may in turn affect the traits of individuals through competitive interactions. The effect of temperature on competitive abilities has been mainly tested via inter-specific experiments (Park, 1954; Tilman, Mattson, \& Langer, 1981; Gherardi, Coignet, SoutyGrosset, Spigoli, \& Aquiloni, 2013) and models (Vasseur \& McCann, 2005; Gilman, Urban, Tewksbury, Gilchrist, \& Holt, 2010). But very little is known on the effect of temperature on intraspecific competition, which is one of the factors known to modulate populations' responses to temperature variation (Bassar, Letcher, Nislow, \& Whiteley, 2016).
In natural populations the direct temperature effects on individual traits and the indirect effects through density dependence are necessarily confounded: disentangling these two types of effects in natural population is a difficult task. In particular, we lack experimental data that quantifies how temperature affects intraspecific competition. A theoretical study proposed two alternative hypotheses on the temperature-dependence of intraspecific competition in ectotherms (Amarasekare \& Coutinho, 2014). First, the strength of intraspecific competition can increase monotonically with the temperature. This is expected when resource requirements increase with temperature due to higher activity levels (Brown, Gillooly, Allen, Savage, \& West, 2004; Ohlberger, Edeline, Vøllestad, Stenseth, \& Claessen, 2011; Savage, Gillooly, Brown, West, \& Charnov, 2004). In this scenario, direct and indirect effects of temperature act synergistically: above a physiologically optimal temperature, direct negative effects of warming will be amplified by a monotonically increasing strength of competition with increasing temperature. Alternatively, the strength of intraspecific competition can reach a maximum at an intermediate temperature, which is near the optimal temperature for reproduction (such as in the example of the bordered plant bug in (Johnson et al., 2015)). The increase of resource uptake required to maximize reproduction at intermediate temperatures strengthens competition (Amarasekare \& Coutinho, 2014). In this second scenario, direct and indirect effects will act antagonistically: above the thermal optimum, warming will have a direct negative effect but an indirect positive effect due to the loosening of the strength of competition with increasing temperatures. This is expected to generate more complex demographic responses (Amarasekare \& Coutinho, 2014). Note that for temperatures below the optimal temperature (where the TSR is defined), the two hypotheses have the same predictions as direct and indirect effects always act antagonistically.

We propose here to use experimental data to (1) estimate a range of temperature that are optimal for reproduction and (2) to provide a direct quantification of the shape of the relation between the competition and temperature (a sort of "intraspecific-competition thermal reaction norm") and to determine which theoretical scenario this empirical relation is closest to.

Within-species genetic variability can add an other level of complexity on this interaction between temperature and competition: the strength of competition and the way it varies with temperature can vary between different lineages or populations. And a variation in the shape of this intraspecific-competition thermal reaction norm could be associated with different demographic responses as mentioned above (Amarasekare \& Coutinho, 2014).

Here we aimed to study experimentally the joint effect of competition and temperature on life history. We focussed specifically on two traits potentially affected by competition and temperature: growth rate and asymp- 
totic length. And we used, as an experimental model, the parthenogenetic Collembola Folsomia candida (Willem, 1902), an apterygotous hexapod that continues to moult and reproduce throughout life and where the body size is a primary determinant of the size of clutches laid by an individual. We compared two clonal lineages to study how within-species variations at individual level integrate with demography.

This leads us to address the next three questions:

(1) How are the thermal reaction norms of growth rate and asymptotic length measured on isolated individuals modified in populations regulated by competitive interactions?

(2) How does the temperature modify the strength of the intraspecic competition on these two traits?

(3) How important the within-species genetic variation of thermal reactions norms of growth rate, asymptotic length and of the strength of competition can be?

To address these questions, we measured in parallel, in two genetically distinct clonal lineages, the responses of both isolated individuals and populations of Collembola maintained at six different temperatures (Fig. 1).

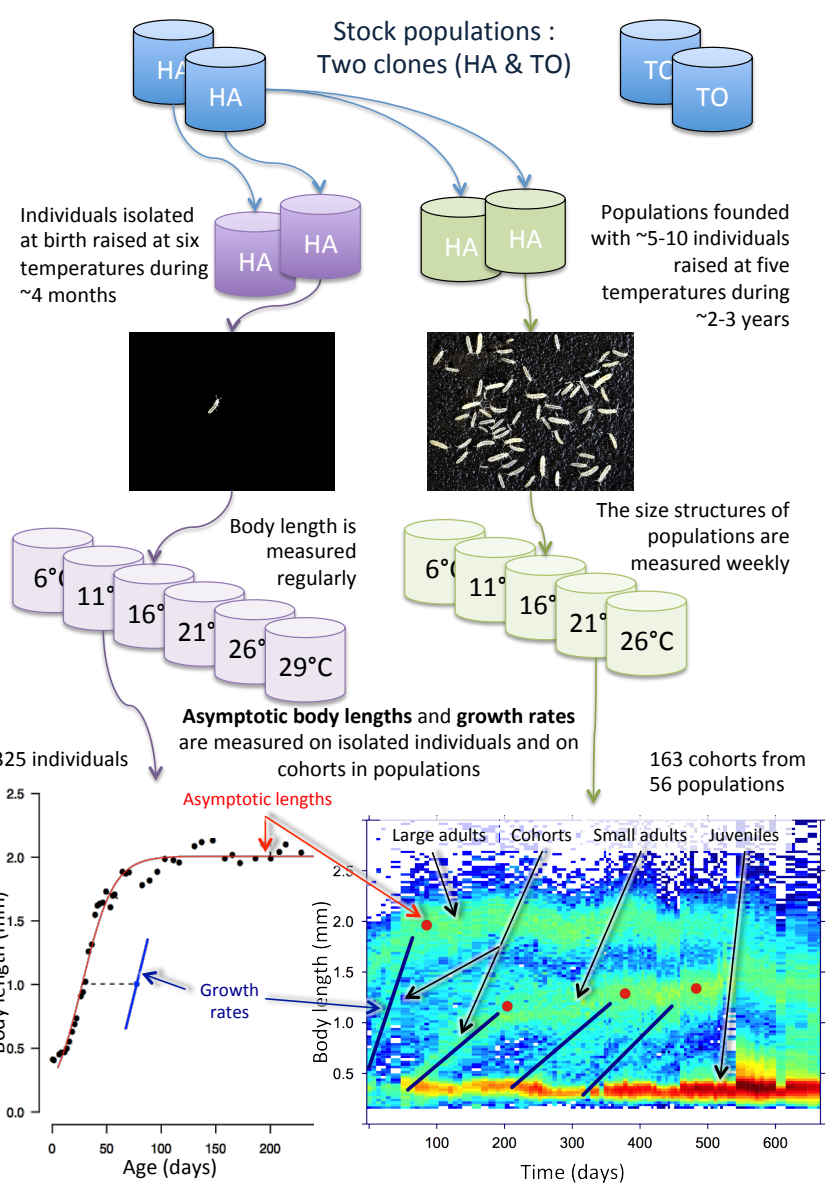

Figure 1: Experimental design. Two genetically different clonal lineages have been studied (HA \& TO). Isolated individuals and populations have been maintained and studied at respectively six and five temperatures. Growth trajectories and long-term structure population dynamics (also called structure time diagrams) have been used to measure asymptotic body lengths and growth rates. Structure time diagrams display temporal dynamics of the populations' size-structure: for each time (x-axis) and size class (y-axis) coordinate, a colour rectangle is plotted whose hue refers to the number of individuals on a log scale (warmer colours reprensent higher abundance). Dark blue lines are examples of some measurements of cohort growth rates. Red dots are estimates of the mean asymptotic length attained by these cohorts. Note that in some populations such as the one displayed here (HA maintained at $21^{\circ} \mathrm{C}$ ), the size structure can be trimodal with two modes of adults coexisting with the mode of juveniles. In such cases, adult cohorts whose mean asymptotic body lengths remain below $1.5 \mathrm{~mm}$ are referred to as "small adults". See main text for details. 


\section{Materials and methods}

\section{Experimental setup}

We used the Collembola Folsomia candida - a small ( 2 $\mathrm{mm}$ long) blind ametabolous hexapod - as a model organism to run experiments on both isolated individuals and populations. Details on rearing conditions and lineages used in experiments can be found in the Supporting Information section. Briefly, we followed individuals from two clonal lineages (labelled TO and HA) either isolated or in populations at six different temperatures $\left(6^{\circ}, 11^{\circ}, 16^{\circ}, 21^{\circ}, 26^{\circ}\right.$ and $\left.29^{\circ} \mathrm{C}\right)$. These two lineages have two contrasted life history strategies along a slow (HA) - fast (TO) continuum (Mallard, Farina, \& Tully, 2015; Tully \& Ferrière, 2008) and may differ in their competitive abilities. In this species, the strength of competition is expected to increase with adult density because large individuals are known to monopolise food sources through interference competition (Le Bourlot, Tully, \& Claessen, 2014; Le Bourlot, 2014) and with the rate of reproduction which reflects the resource requirements (Tully \& Ferrière, 2008).

Individuals were followed from hatching until death and size-structure of populations was measured weekly for more than a year. Populations were kept long enough (several months or years) to allow them to regulate themselves with density dependence. Competition between individuals is therefore intense in these monoclonal populations. Populations are self-regulated by the resource - delivered weekly - that is kept constant over time and between temperatures. This resource became progressively limiting in every populations (i.e. no remaining food after a week) except at $6^{\circ} \mathrm{C}$.

We only studied monoclonal populations. Therefore, competition only occurred between individuals sharing the same genotype. We did not study how the two lineages interact with each other.

\section{Measurements made on isolated individuals}

Reproduction. Containers were regularly inspected for eggs in order to count the number of clutches and eggs laid by each individual $(n=185)$ during the experiment (400 days). The total number of eggs laid by each individual was used as an overall measurement to determine optimal temperatures for reproduction (Fig. 2A).

Growth rate and asymptotic body length of isolated individuals. During the first ten weeks of the experiment, individuals were measured three times per week. Then, after ten weeks, when their growth has slowed down, they were measured once a week. This was done until all individuals died (400 days, $95 \%$ of the individuals died before 230 days). For each body length measurement, two to three pictures were taken using a digital camera (Nikon D300) fixed on a dissecting scope. Body length was measured on each picture using the Image J software (Abramoff, Magalhaes, \& Ram,
2004) (http://rsbweb.nih.gov/ij/). More precisely, we measured the length from the front of the head to the rear of the abdomen on pictures taken from above such as the one visible on Fig. 1. This measurement was done using the "segmented line selection tool", after calibrating units with the "set scale" command. Smoothed splines growth curves were fitted to each individual growth trajectory (Fig. 1) using the function gcFitSpline from the package grofit with a Gompertz type function. We adjusted the smoothness of the spline fit so as to generate estimates of growth parameters that are comparable to the ones measured on populations (see Fig. S1 for details). Growth rates and asymptotic lengths were estimated from these fits (parameters $m u$ and $A$ ).

\section{Measurements made on cohorts in populations}

Dynamics of the population size structure. The population size structure was measured weekly during more than a year using a dedicated program. Each measurement gave us the number of individuals and, for each individual counted, its body length ( $\mathrm{mm})$. Given the number of Collembola in a box, and that individual marking is unattainable, it was not possible to measure the asymptotic body length and growth rate of an individual in a population. But we managed to extract measurements of these life history traits in populations using the graphical representation for structured time series (Fig. 1 and Fig. S2) provided by the R package STdiag (Le Bourlot, Mallard, Claessen, \& Tully, 2015). The examination of the structure time diagrams reveals many breakaway waves of density through time in populations (Fig. 1). These waves of density - which we call "cohorts" - connect small to large individuals over time and result from the synchronised growth of a group of small Collembola within the group of larger individuals (See the "Cohort" in the bottom right panel of Fig. 1 and for example the TO_06_r2 and TO_06_r4 populations in Fig. S2). We visually inspected the structure time diagrams of our 56 populations to identify 163 cohorts that are sufficiently contrasted graphically to be studied quantitatively (Fig. 1, Fig. S2, Fig. S3). Note that we did not take into account juveniles that, for different reasons, never managed to grow, or those that did not grow in a cohort and whose growth trajectories were thus invisible on graphs.

Mean growth rate and asymptotic body length in populations. We measured the mean growth rate and asymptotic body length of the 163 distinct cohorts that we identified. The black segments on the structuretime diagram of Fig. 1 (bottom right panel) shows how we measured the mean growth rate in the populations: it is the slope of a line adjusted by eye through visible growing cohorts (waves). We adjusted a strait line rather than a growth curve because many cohorts that are well distinguishable during their period of maximum growth are less well distinguishable before and after this period especially when they merge with other cohorts. Fig. S1 details how we compared growth of isol- 
ated individuals and of cohorts. The asymptotic body length was estimated visually as the mode length of individuals once the growing cohort had fully merged with pre-existing adults, or when the mode length of the growing cohort stabilizes (black dots on the structure-time diagram of Fig. 1). Note that in some HA populations at $21^{\circ} \mathrm{C}$, two modes of large individuals could be identified: some of the measured cohorts produced large fully-grown individuals $(>1.5 \mathrm{~mm})$ while others produced individuals that stabilised their growth at smaller sizes ( $<1.5 \mathrm{~mm}$, Fig. S2 and Fig. 3B). More details on these measurements are provided in Supporting Information section and in Fig. S1.

Measuring densities of large and small individuals. Using the R package STdiag, we also extracted mean densities of adults and juveniles. More technical details can be found elsewhere (Le Bourlot et al., 2015) and in Supporting Information. Individuals are considered as juveniles if they are shorter than $0.3 \mathrm{~mm}$ and as large if they are longer than $0.9 \mathrm{~mm}$ based on the multimodal body length distributions in the populations (Fig. S6). We use the term "adult" to designate large individuals in populations although it does not mean that they are all reproductive adults since we cannot measure the size at maturity in populations.

\section{Measuring the joint effects of tem- perature and intraspecific competition on growth rates and asymptotic lengths}

In populations, changes in growth rates and asymptotic body lengths are expected to be determined by direct effects of temperature (warming increases growth rate and downsizes body length) and by direct effects of intraspecific competition (density dependence). But temperature can also intervene through indirect effects by modifying the population density and the strength of intraspecific competition.

To study whether indirect effects of temperature (via competition) alter patterns seen at the individual level, we first compared isolated individuals with cohorts, without considering the effect of density within populations (Fig. 3, Table 1, Table 2). We then took advantage of long-term variations of adult densities within populations (Fig. 2B \& Fig. S2) to quantify the strength of competition for each combination of temperature and lineage (Figure 4, Table S1) and to study if, and how, the strength of competition changes with temperature (Figure 5A, B). The strength of intraspecific competition on growth and length was estimated as the effect of the logarithm of adult density on growth rates and asymptotic lengths (Table S1, Fig. 2B).

To quantify the direct effects of temperature in populations, we controlled for density by scaling all populations as if adult densities in containers was constant and equal to 100 adults (Fig. 5C, D). This corresponds to a density observed in almost every combination of lineages and temperatures (Fig. 2B) and is close to the overall mean adult density observed in the populations (overall mean: 103 adults per container).
Lastly, to better visualize the joint effects of temperature and density on the two traits, we grouped the measurements made on isolated individuals ("adult density" of zero) and those made in populations at the different adult densities to draw a $3 \mathrm{~d}$ contour plot using the function stat_contour from the ggplot2 library (Fig. S7).

\section{Statistical analysis}

All analyses were done with R 3.3.1 software http:/ /cran.r-project.org (Ihaka \& Gentleman, 1996) and we used the package ggplot2 to produce the graphics (Wickham, 2009).

Statistical models. We used Gaussian linear models ( $g / m$ function) to study the growth rate and asymptotic length. We started with full models with all dependent variables and their interactions and simplified these models by removing non-significant interactions. The factors lineage (the two clones) and temperature were included in the initial models. The effects and their interactions are tested with type 3 anova (Anova function from the package car). In statistical tables (Table 1, Table 2, Table S1) we report in italics the tests corresponding to complex interactions that have been dropped from the full models and results of the type 3 anova on simplified models. We performed several complementary analyses on subsets of the whole datasets to better understand complex interactions and to perform specific comparisons. For instance, when we found one or several significant interactions between lineages and other variables, we performed some independent sub-analyses on each genetic line to better understand each of their specific responses.

Temperature. Temperature often had nonlinear effects. Thus in the statistical models we generally considered temperature as a categorical variable with 6 levels for isolated individuals and 5 levels for the populations $\left(29^{\circ} \mathrm{C}\right.$ missing) to avoid imposing a priori a parametric response. In some models, or for some specific comparisons, we sometimes considered the temperature as a continuous variable when the response to temperature was visually linear (between $6^{\circ}$ and $26^{\circ} \mathrm{C}$ for the growth rate of isolated individuals for instance, Fig. 3A, B).

Graphics. We do not report values of estimates from the models in the tables but we refer to the graphics that have been designed to help understand and support the statistical analysis. Means and their 95\% confidence intervals on figures, and log-linear relationships and their 95\% confidence intervals in Fig. 4 were estimated using saturated models including all the complex interactions. We used these saturated models to produce figures that reveal the data with minimal constrains (Tufte, 2001). Estimates and 95\%confidence intervals of parameters of the saturated models are provided in Table S3.

\section{Results}




\section{density.}

\section{Temperature, reproduction and adult}

Reproduction. Cumulative reproduction of isolated individuals is reduced at the lowest temperature extreme $\left(6^{\circ} \mathrm{C}\right)$ and is absent at the highest one $\left(29^{\circ} \mathrm{C}\right)$ for both lineages. At $6^{\circ} \mathrm{C}$, growth is so slow that it takes more than 100 days for most individuals to reach maturity. At $29^{\circ} \mathrm{C}$, the reproductive cessation could result from the asymptotic body lengths of individuals $(\leq 1 \mathrm{~mm}$, see below) being smaller than the average size at maturity at $29^{\circ} \mathrm{C}(\sim 1.2-1.4 \mathrm{~mm})$ (van Dooren, Tully, \& Ferrière, 2005). Between these extremes, the mean cumulative reproduction has an unimodal bell-shaped thermal response curve with a maximum reproduction reached at a lower temperature for $\mathrm{TO}\left(\sim 16^{\circ} \mathrm{C}\right)$ than for $\mathrm{HA}\left(\sim 21^{\circ} \mathrm{C}\right.$, Fig. 2A, B). TO has on average a higher fecundity than HA (Fig. 2A, B, Fig. S4A). For both lineages, the mean clutch size measured on the first 5 clutches decreases with increasing temperature but TO lay larger clutches than HA (Fig. S4A). On average, at low temperature, springtails lay larger clutches but less often than at warmer temperatures.

Adult and juvenile density. We counted on average 100 large individuals per population but this number ranged from less than 20 to more than 200 because of long-term fluctuations in populations' densities and structures (Fig. 2C, Fig. S2). The average adult density is low at the two temperature extremes, and reaches a maximum between $11^{\circ}$ and $21^{\circ} \mathrm{C}$ (Fig. 2C). Adult densities do not significantly differ between lineages. The density of juveniles is also variable within and across treatments. Below $21^{\circ} \mathrm{C}$, TO populations bear on average more juveniles than HA (Fig. S4B).

The measurements made on isolated individuals suggest that the optimal temperature (in term of reproduction) for HA is higher than the one of TO. It was not possible to measure the fecundity in the populations to test if these differences in optimal temperatures also apply in populations but the number juveniles observed in populations could be interpreted as an indirect proxy of reproduction (Fig. S4B) and the temperature dependence of juvenile density in populations echoes the effect of temperature on the reproduction of isolated individuals: both observations support the idea that the optimal temperature for reproduction of $\mathrm{HA}$ is a bit higher on average that the one of TO. This suggests that the difference in "optimal temperature" for reproduction observed on isolated individuals is at least partly relevant for identifying differences in optimal temperature in populations.
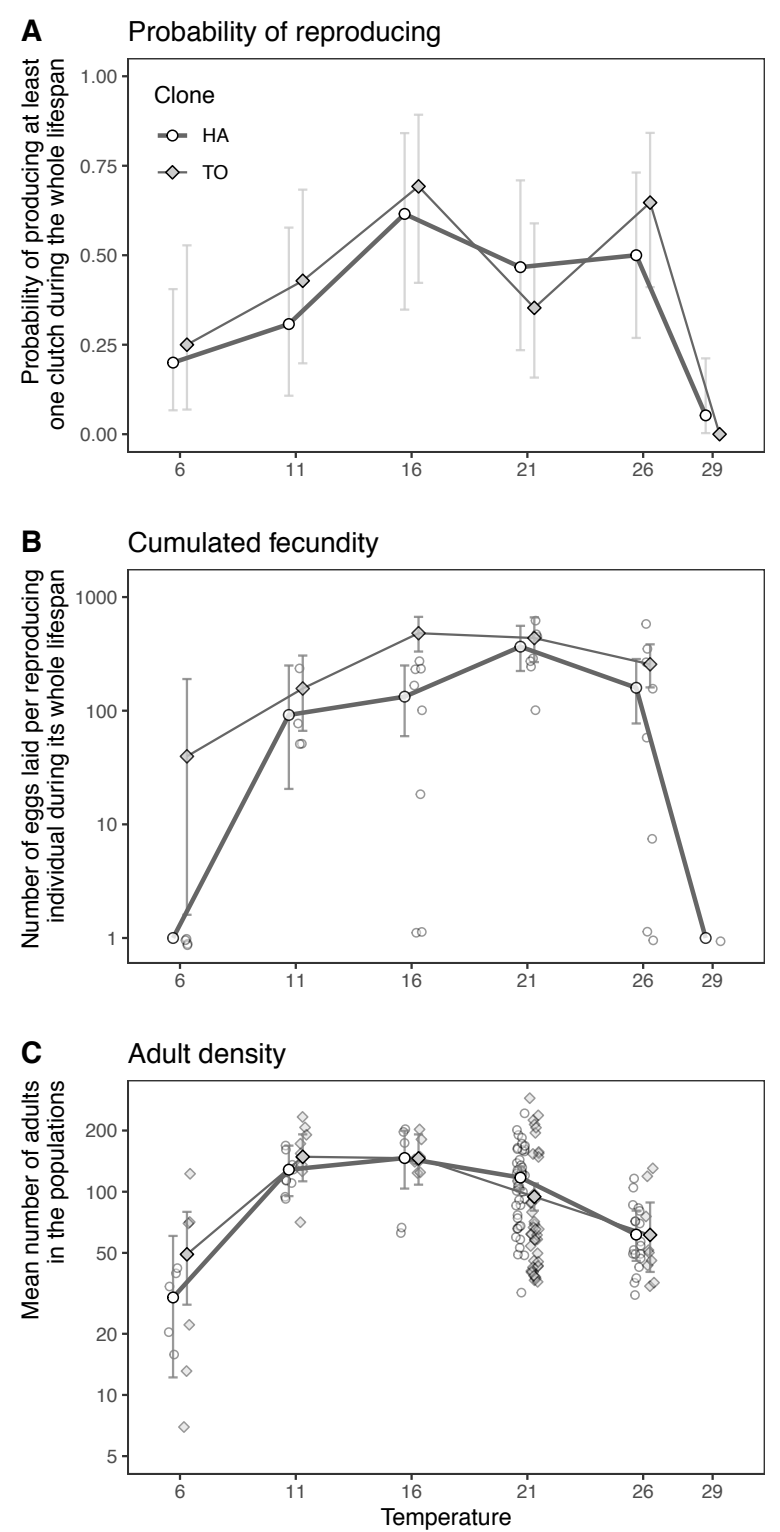

Figure 2: The effects of temperature on reproduction of isolated individuals (A, B) and on adult density in populations (C) for lineages HA (open circle) and TO (grey diamonds). The panel A represents the estimated probability of reproducing (and estimated $95 \% \mathrm{Cl}$ with a binomial model) of the isolated individuals as a function of temperature. The probability of reproducing is maximal for both clones between $16^{\circ}$ an $26^{\circ} \mathrm{C}$. Panel $\mathrm{B}$ displays the total number of eggs laid by the reproducing individuals during their whole life and the mean and 95\% confidence interval for each combination of temperature and clone estimated with a quasipoisson linear model. Mean cumulated fecundity (B) peaks around $21^{\circ} \mathrm{C}$ for $\mathrm{HA}$ and around $16^{\circ} \mathrm{C}$ for TO. The panel $\mathrm{C}$ displays adult densities measured in populations at the time of measurements of growth and asymptotic length (see methods for details). On average, maximum adult densities are reached between $11^{\circ} \mathrm{C}$ and $21^{\circ} \mathrm{C}$.

\section{The effect of temperature on growth}

\section{rate}

Individuals versus populations. A full model combining measurements made on isolated individuals and on cohorts shows that the growth rate is influenced by a complex interaction between lineage identity, temperature and competition treatment (isolated individuals 
versus population) and by an interaction between temperature and competition (Table 1A, Fig. 3A): isolated individuals grew on average 4.2 time faster than cohorts in populations on the whole temperature range but the difference between the two competition treatments was stronger for intermediate temperatures (5.6 times faster at $16^{\circ} \mathrm{C}$ and 5.9 times faster at $26^{\circ} \mathrm{C}$, Fig. $3 A)$. The average effect of temperature on growth rates of isolated individuals $\left(+2.74 \mu \mathrm{m} / \mathrm{day} /{ }^{\circ} \mathrm{C}\right.$, average estimated over the two lineages) is 8.7 times higher that the mean effect of temperature on growth rates in populations $\left(+0.31 \mu \mathrm{m} /\right.$ day $/{ }^{\circ} \mathrm{C}$, Fig. $\left.3 \mathrm{~A}\right)$. We further split the data to examine the effects of temperature and lineage identity in each competition treatment separately (isolated individuals/populations).

Individuals. Growth rates of isolated individuals depend on an interaction between lineage identity and temperature but, as expected, the effect of temperature was massive for both lineages (Table 2A). Growth rates increase almost linearly with temperature (Fig. 3A) between $6^{\circ}$ and $26^{\circ} \mathrm{C}\left(2.56 \pm\right.$ SE. $0002 \mu \mathrm{m}$. day $^{-1} .{ }^{\circ} \mathrm{C}^{-1}$, 95\% Cl: 2.22-2.29). They then drop between $26^{\circ}$ and $29^{\circ} \mathrm{C}$. Both lineages have similar growth rates on the whole temperature range except at $26^{\circ} \mathrm{C}$ where TO grows on average $30 \%$ faster than $\mathrm{HA}(\mathrm{t}=4.06, \mathrm{p}=$ 0.0023).

Populations. Growth rates measured in populations did not differ between clonal lineages but varied slightly with temperature (Table $2 \mathrm{~B}$ ): on average, cohorts are growing $75 \%$ faster at $26^{\circ} \mathrm{C}$ than at the colder temperatures combined (contrast between $26^{\circ} \mathrm{C}$ and the four other temperatures $F_{1,162}=35.7, p<0.001$ ) while the growth is uniformly low over the four lower temperatures $\left(F_{3,131}=1.7, p=0.17\right)$.

\section{A Growth rate}

HA

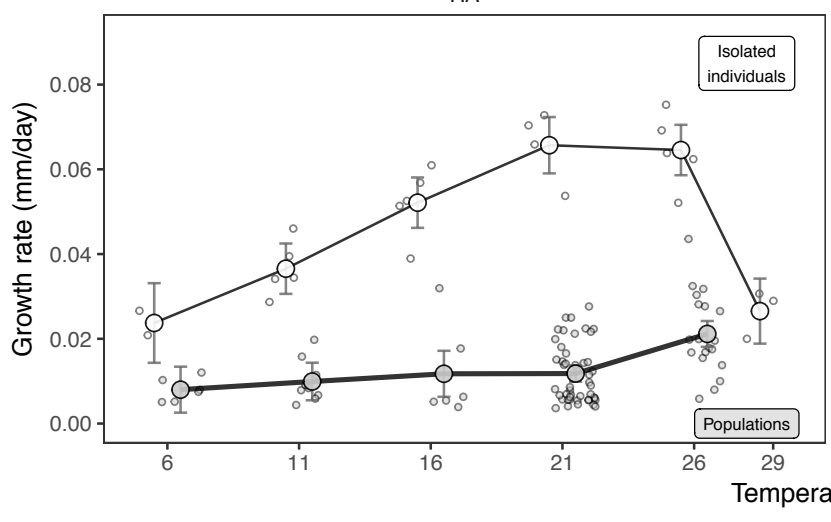

TO

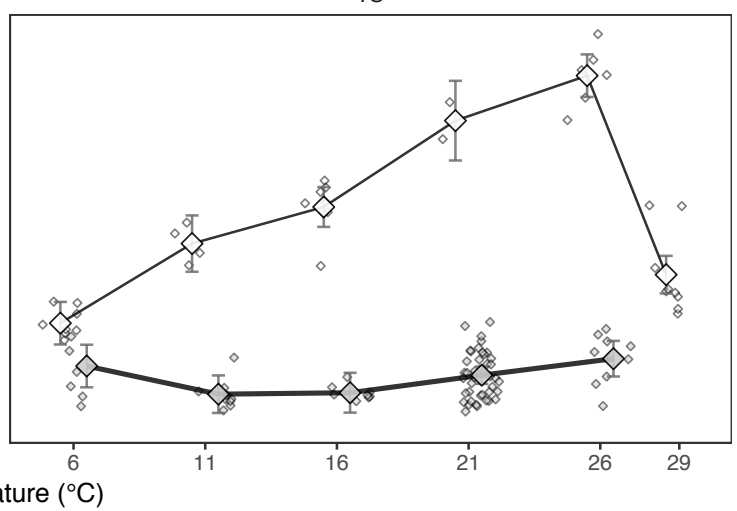

B Asymptotic body length

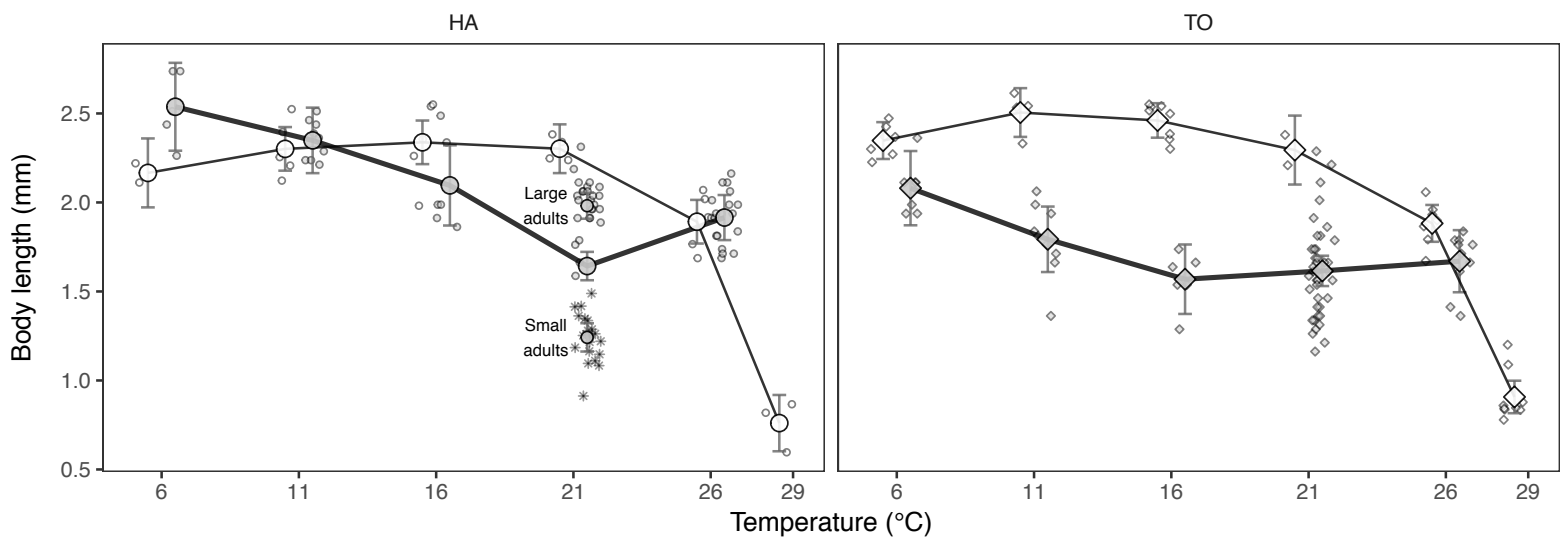

Figure 3: The thermal reaction norms of growth rate (A) and asymptotic body length (B) for lineages HA (left, circles) and TO (right, diamonds). Means (and 95\% confidence intervals) are plotted for each combination of lineage identity, temperature and type of measurement (isolated individuals and cohorts in populations) together with the raw measurements. Open symbols and fine line are used for measurements made on isolated individuals and symbols filled with grey and thick solid lines are used for measurements made in populations. Asterisks are used to represent small adults observed in some $\mathrm{HA}$ populations at $21^{\circ} \mathrm{C}$. Note that at $29^{\circ} \mathrm{C}$ we only plot measurements made on isolated individuals because we failed at maintaining populations at $29^{\circ} \mathrm{C}$ since individuals do not reproduce at this temperature (Figure $2 \mathrm{~A}$ ).

The effect of temperature on asymptotic body length
Individuals versus populations. Using the whole dataset, we found that the asymptotic body length is affected by significant two-way interactions between 
competition (isolated individuals versus populations), lineage identity and temperature (Table 1B).

For $\mathrm{HA}$, the asymptotic body length in population is very close to the length reached by isolated individuals except at $21^{\circ} \mathrm{C}$ where on average the small and large adults in populations are smaller than the isolated ones (Fig. 3B, large adults $x^{2}=16, p<0.001$ ). Thus, for $H A$, $21^{\circ} \mathrm{C}$ is the only tested temperature where the asymptotic length in populations is smaller than the asymptotic length of isolated individuals $(-0.66 \mathrm{~mm} \pm$ $\mathrm{SE}=0.20$ in populations, $\mathrm{X}^{2}{ }_{1}=10,7, \mathrm{p}=0.001$ ).

Contrary to what was observed for $\mathrm{HA}$, the asymptotic body length of TO in populations is significantly smaller than the asymptotic length of isolated individuals on the whole temperature range (comparisons for the five temperatures, $\left.X^{2}{ }_{1}>8.4, p<0.04\right)$. The difference between the two competition treatments is maximum at $16^{\circ} \mathrm{C}\left(-0.9 \mathrm{~mm} \pm \mathrm{SE}=0.06\right.$ in populations, $X^{2}{ }_{1}=233$, $\mathrm{p}<0.001$, Fig. 3B).

Individuals. Lineage identity and temperature have additive effects on the asymptotic body length (Table $2 \mathrm{C}$ ). On average isolated TO manage to reach a slightly larger asymptotic length than HA over the whole temperature range $\left(+0.105 \mathrm{~mm} \pm \mathrm{SE}=0.037, \mathrm{x}^{2}{ }_{1}=8.0, \mathrm{p}=\right.$ 0.005 , Fig. 3B). For the two clonal lineages, the asymptotic length of isolated individuals decreases non-linearly with temperature: the average length remains stable between $6^{\circ}$ and $21^{\circ} \mathrm{C}\left(\mathrm{x}^{2}{ }_{1}=1.07, \mathrm{p}=0.30\right)$ and then decreases abruptly between $21^{\circ}$ and $29^{\circ} \mathrm{C}$ (Fig. $3 \mathrm{~B})$ which is outside the optimal thermal range given that growth no longer increases with increasing temperature above $\sim 21-26^{\circ} \mathrm{C}$ (Fig. 3A). Thus, given that the temperature size rule is expected to occur for nonstressful temperatures (Atkinson, 1994; Walczyńska et al., 2016; Hoefnagel et al., 2018), isolated individuals appear to slightly or even not really follow the TSR, especially $H A$ since its mean asymptotic lengths remain roughly stable on its non-stressful thermal range.

Populations. Lineage and temperature have additive effects on the mean asymptotic length in populations (Table 2D). Yet, HA that is on average larger than TO over the whole range of temperatures $(+0.4 \mathrm{~mm} \pm \mathrm{SE}=$ 0.03 , Fig. 3B). The mean asymptotic length declines regularly between $6^{\circ}$ and $21^{\circ} \mathrm{C}$ for $\mathrm{HA}$ and between $6^{\circ}$ and $16^{\circ} \mathrm{C}$ for TO $\left(\sim-0.048 \mathrm{~mm} .{ }^{\circ} \mathrm{C}^{-1}\right)$. Above these temperatures it either increases slightly $(\mathrm{HA})$ or remains roughly constant (TO).

\section{The joint effects of temperature and density in populations}

\section{Growth rates}

The full model that combines the two lineages shows that growth rates depend on two-ways interactions between lineage, temperature and adult density (Table S1We further split the dataset to analyse separately the response of the two lineages (Table $1 \mathrm{~B}, \mathrm{C})$. We found that for both lineages growth rates of cohorts were determined by an additive effect of the adult density and the factor temperature (Table S1B, C), which means that intraspecific competition (adult density on a log scale) had on average the same negative effect on growth rates for each temperature (Fig. 4A \& Fig. 5A). For both lineages, the additive effect of temperature vanishes for temperatures above $6^{\circ} \mathrm{C}$ (Table S1B, C). To better understand the biological meaning of the additive effect of temperature in populations for the two lineages (and its interaction with lineage identity in the main model Table S1A), we plotted the predicted growth rates for the different temperatures in a virtual population where the adult density is fixed to 100 adults (Fig. $5 \mathrm{C}$ ). This shows that, at this density, the growth rate is not influenced by temperature for TO but tends to decrease with increasing temperatures between $11^{\circ}$ and $26^{\circ} \mathrm{C}$ for $\mathrm{HA}$, although this change is not significant given the overlaps of the confidence intervals. Thus we conclude that at this adult density (100 ind.) the temperature has very limited direct effect on growth rates, which are mainly determined by the strength of intraspecific competition.

\section{Asymptotic body length}

In the full model that combines the whole dataset, the asymptotic body length in populations is affected by two significant interactions, temperature ${ }^{*}$ density and lineage identity ${ }^{*}$ temperature (Table S1D). The first interaction means that the strength of intraspecific competition on length changes with temperature, similarly for the two lineages. This is visible on the Fig. 5B, which reports estimated values of an unconstrained fully saturated model (the one with all possible interactions). Competition is minimal at $6^{\circ} \mathrm{C}$ (see also the flat relation in Fig. $4 \mathrm{~B}$ at $6^{\circ} \mathrm{C}$ ) and maximal at $11^{\circ} \mathrm{C}$. It then decreases progressively as the temperature increases.

As for the growth rates, we used the full model to predict - and plot - the asymptotic body length at the different temperatures in a population comprising 100 large individuals (Fig. 5D). This figure shows that the asymptotic body length decreases as temperature increases when the effect of density is controlled $\left(-0.024 \mathrm{~mm} /{ }^{\circ} \mathrm{C} \pm \mathrm{SE}=0.002\right.$ on average between $6^{\circ}$ and $26^{\circ} \mathrm{C}$ ) and that $\mathrm{TO}$ is on average smaller than $\mathrm{HA}$ $(-0.41 \mathrm{~mm} \pm \mathrm{SE}=0.03)$ over the temperature range. The significant interaction between temperature and adult density for TO (Table S1F) is due to the better estimation of the strength of competition at $6^{\circ} \mathrm{C}$ compared to HA (Table S1E) for which we had fewer cohorts in populations raised at $6^{\circ} \mathrm{C}$ to estimate the asymptotic length. 
A

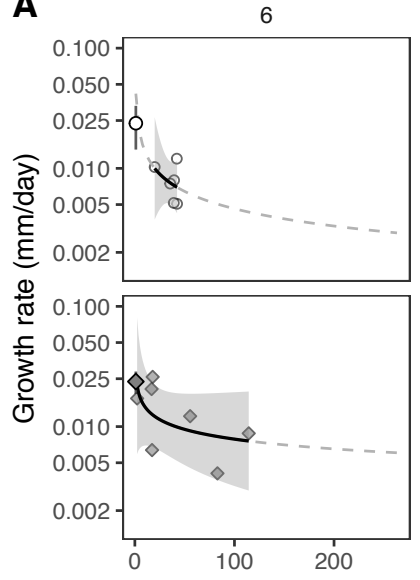

B

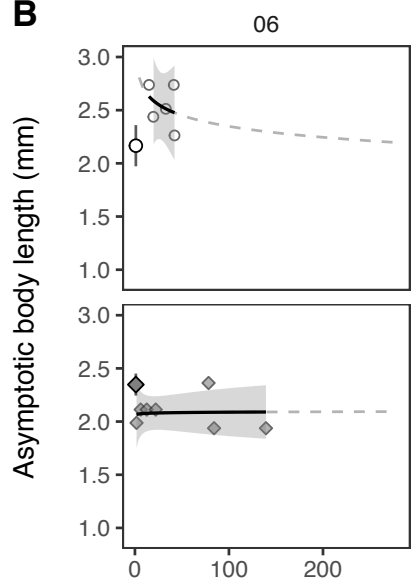

11

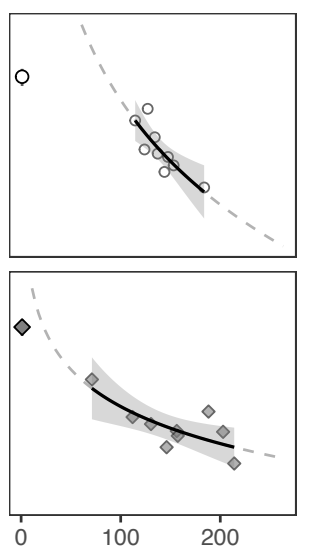

11

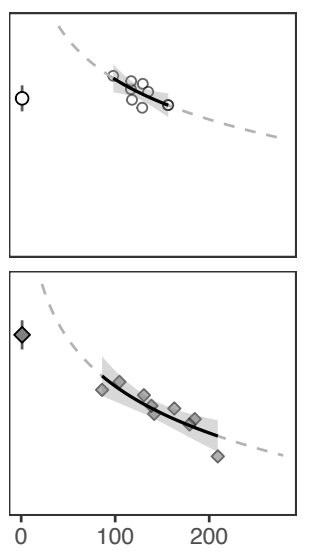

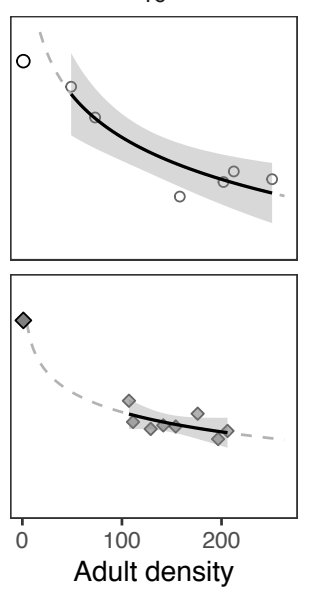

16

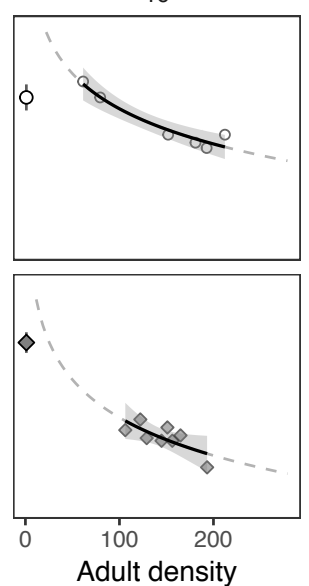

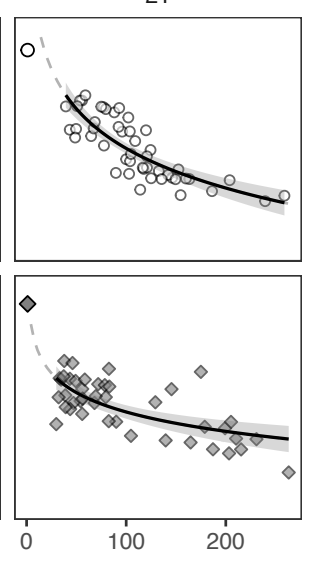

21

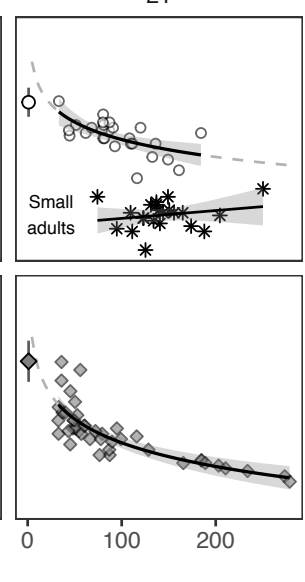

26

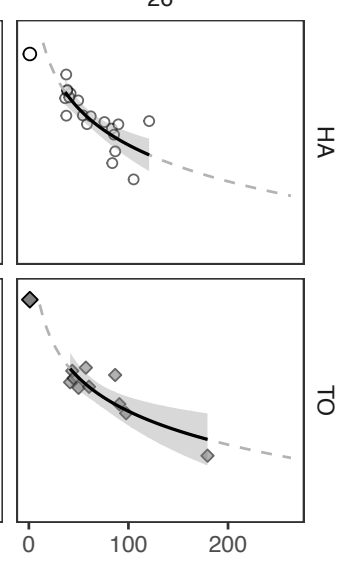

26

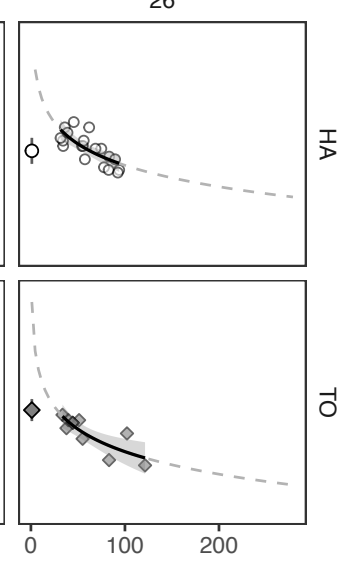

Figure 4: The joint effects of temperature (four columns of panels) and adult density (mean number of adults per container) on cohort growth rates (A) and asymptotic body length in populations (B) for the two lineages HA (open circles) and TO (filled diamonds). On the left side of each panel the mean growth rate and asymptotic body lengths $(95 \% \mathrm{Cl})$ measured on isolated individuals (Figure $4 \mathrm{~A}$ and $\mathrm{B}$ ) are plotted for comparisons. Growth rates are plotted on a log10 scale. The function adjusted to the data is a linear fit of the form $y=a+b^{*} \log (x)$, $x$ being the mean density of large adults at the time of the measurement. It is prolonged out of the range of the data with a dotted curve. The size of the "small" adults observed in the HA populations at $21^{\circ} \mathrm{C}$ are plotted with asterisks. 
Strength of intraspecific competition
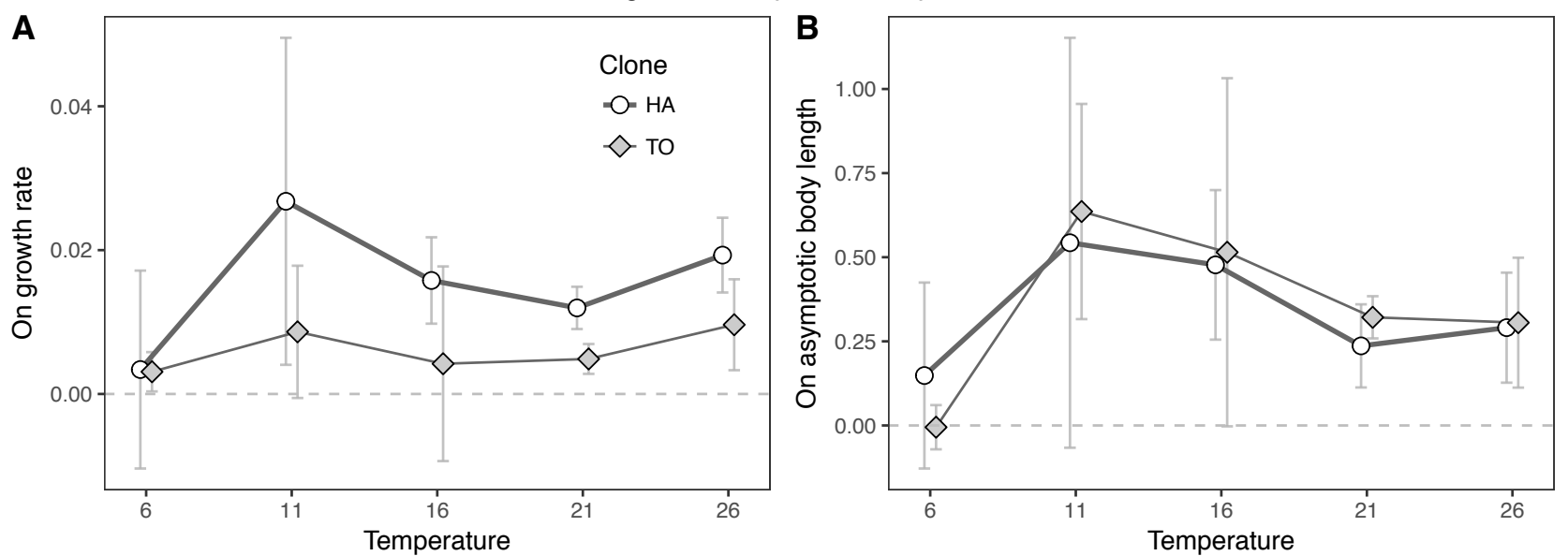

Estimates scaled for a density of 100 adults
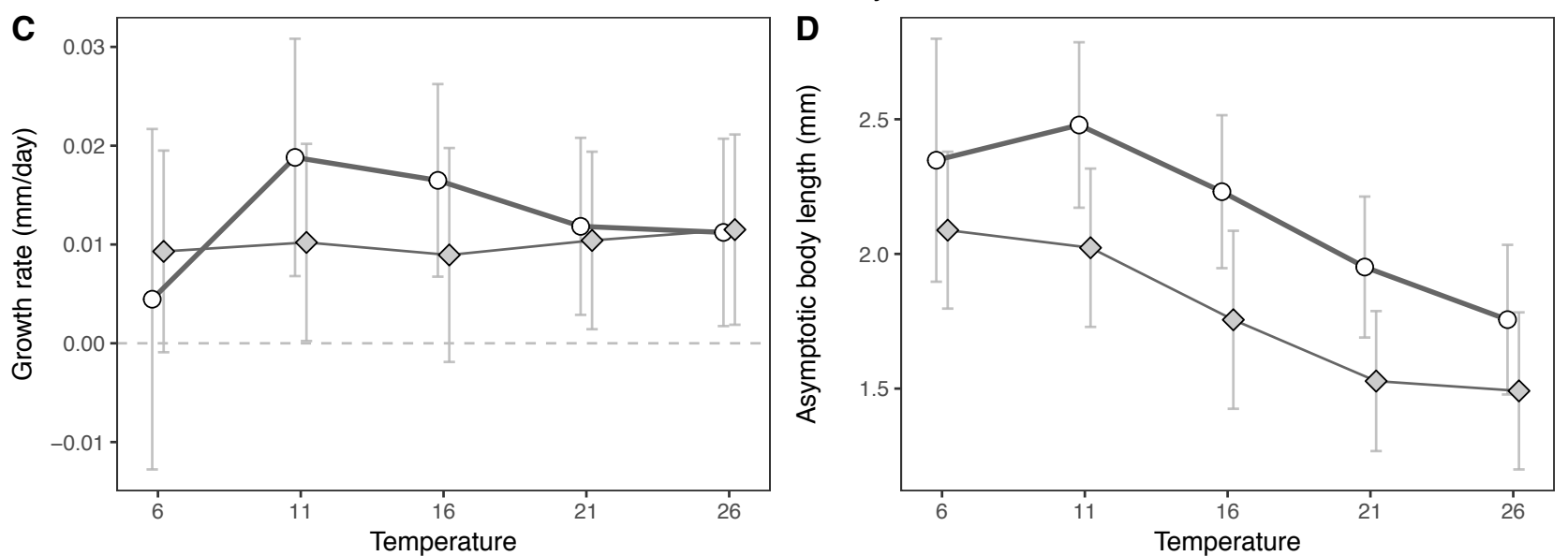

Figure 5: The strength of intraspecific competition on growth rate and body length within populations has been estimated as the slope (reversed to positive values) of the effect of adult density (log scale) on the growth rate (A) or asymptotic body length (B) estimated independently here for each lineage and temperature (mean $\pm 95 \%$ confidence intervals). To visually reveal the effect of temperature on the growth rate $(C)$ and asymptotic body length $(D)$ in populations while controlling for density we have plotted the predicted estimates of growth rate and body length for an adult density scaled at 100 individuals per box using an unconstrained linear model with an interaction between lineage and temperature.

\section{Analysing the contour plot}

Lastly, the Fig. S7 combines all the measurements that we made on isolated individuals and in populations to better understand visually the joint and non-linear effects of competition (density) and temperature. For TO, the intraspecific competition has a negative effect on asymptotic length with an additive effect of temperature that remains on almost the whole range of conditions explored. For HA, the density has first a positive effect on asymptotic length: when the adult density increases, the collembola tend to reach a longer asymptotic body length. But when the density continues to increase (above 50 individuals per container), its effect becomes negative.
Note that when comparing isolated individuals to populations we found that asymptotic lengths of HA are marginally modified in populations (Fig. 3B), which seems to be in contradiction with the observed effect of intraspecific competition on this trait (Fig. 5B). This is because density has first a positive effect on body length in this lineage (adults in small populations are larger than isolated individuals). This non-linear effect of density (visible on Fig. 3B and Fig. S7B) underlines the advantage of quantifying the strength of intraspecific competition by comparing populations with different densities rather than relying simply on the comparison of populations with isolated individuals since this would have led to conclude that competition has no effect on this trait. 


\section{Discussion}

We aim to understand how the direct effects of temperature on the life history of individuals are modulated by demographic feedback, i.e., the density-dependent processes due to interactions between individuals and their environment. And this study provides one of the first empirical quantification of the joint effects of temperature and competition.

\section{The effects of competitive interactions of the thermal reaction norms}

The thermal reaction norms of growth rate and asymptotic length measured on isolated individuals are close to what is observed for many other ectotherms (Angilletta, 2009; Atkinson, 1996; Kingsolver \& Woods, 1997): warmer conditions allow for faster growth (Fig. 3A, Fig. 6) and Collembola raised at high temperatures are smaller than those raised at the cold temperatures. But the TSR only slightly applies since a marked decrease in asymptotic body length was only detected above the optimal temperature range, where growth slows down and reproduction declines. The significance of this departure from the strict TSR remains to be determined and it could be interesting to study the potential benefits of a reduced asymptotic size in warm conditions in terms for instance of mortality to study whether this non linear reduction of body length is adaptive.

The effect of density and intraspecific competition on the growth trajectories has been the subject of numerous studies (Sebens, 1987): in many species, individuals grown in crowded conditions show a reduced growth rate and reach a smaller size. As expected we demonstrate that the growth rate of Collembola is reduced in crowded conditions and that, in most conditions, the asymptotic length was also reduced in populations. But in details we found that the shapes of these two thermal reaction norms were modified quite differently in populations. Under competition, growth is slowed down so much that is become uniformly low across the temperature range. This negligible effect of temperature makes sense since the effect of competition is so strong that the growth rate of the cohorts in the populations is comparable to - or even lower than the growth rate of an individual raised at $6^{\circ} \mathrm{C}$. Thus the potential positive effect of temperature on growth is ineffective because temperature is almost never a limiting factor for growth in the populations. Under competition, the temperature-size rule becomes more contrasted: asymptotic length decreases as temperature increases. And the decline in body length $\left(-0.034 \mathrm{~mm} /{ }^{\circ} \mathrm{C}\right.$ on average which corresponds to $\sim-1.7 \%$ reduction in body length per ${ }^{\circ} \mathrm{C}$ increase, Fig. $5 \mathrm{D})$ is within the range of values documented for terrestrial arthropods (Horne, Hirst, \& Atkinson, 2015).

Thus, while temperature seems to have little if no effect on growth rates under competition, the negative effect of temperature on body length is reinforced in Collembola populations. The question whether these re- sponses are specific to our biological model or can be more broadly observed remains open.

\section{The effect of temperature on the strength of the intraspecic competition}

In the introduction, we present two scenarios for the potential effect of temperature on intraspecific competition: according to theory, the strength of competition is supposed to increase with temperature below the temperatures that are optimal for reproduction and can either continue to increase or decrease above this optimal temperature. We provide one of the first empirical quantification of a thermal reaction norm for the strength on intraspecific competition. As expected, the strength of competition increases with temperature below the optimal temperature, but this was visible only for the coldest temperatures (between 6 and $11^{\circ} \mathrm{C}$ ). We fail to show any increase of the strength of competition above $11^{\circ} \mathrm{C}$. Thus, our results do not support the first scenario mentioned above (Amarasekare \& Coutinho, 2014).

The overall bell-shaped curve of the thermal reaction norm of competition on body length suggests that competition intensity is maximal at intermediate temperatures $\left(\sim 11^{\circ} \mathrm{C}\right.$, Fig. $\left.5 \mathrm{~B}\right)$ and decreases with temperature above $16^{\circ} \mathrm{C}$. This broadly supports the second scenario also the congruence between our findings and the theoretical prediction is not perfect because in details the temperature at which competition is the highest is a bit lower than our estimates of optimal temperatures. The second scenario is also in accordance with the observation that the temperatures at which TO and HA's reproduction is maximal $\left(16^{\circ} \mathrm{C}\right.$ and $21^{\circ} \mathrm{C}$ respectively Fig. 2) are also the ones where the two lineages reach their minimal asymptotic body lengths in populations (Fig. 3B). A similar result was described in the bordered plant bug, the effect of competition on fecundity was strongest at temperature optimal for reproduction (Johnson et al., 2015).

The existence of the trimodal adult size distributions at $21^{\circ} \mathrm{C}$ (Fig. 2A) could also be interpreted as complex population dynamics under increased competition as predicted by theory (Amarasekare \& Coutinho, 2014), thus reinforcing the idea that the strength of competition on asymptotic size may be enhanced when reproduction is maximal. And this makes sense given the potential trade-off between investment into reproduction and investment into adult growth to reach a larger asymptotic size in species with indeterminate adult growth trajectories like in the Collembola.

Regarding the trimodal populations, we have previously shown that large adults dominate smaller ones through intense interference competition (Le Bourlot et al., 2014) preventing them from growing further. A similar coexistence of different size classes of individuals has been shown in the lake perch (Persson et al., 2003). In this example, the population is alternatively dominated by stunted or giant individuals due to size-dependent cannibalism and intercohort competition. Here, our 
trimodal structures seem to persist as long as the dominant large adults remain numerous enough but may only establish in a new colonised environment with initially reduced competition for food. But why these complex populations are observed at $21^{\circ} \mathrm{C}$ and not at $11^{\circ}$ or $16^{\circ} \mathrm{C}$, when the strength of competition is supposed to be maximal, remains to be determined.

We failed to detect any significant variation of the strength of competition on growth between $11^{\circ}$ and $26^{\circ} \mathrm{C}$ (Fig. 5A, B) as opposed to our findings on asymptotic length. Given the large confidence intervals (Fig.
5), this discrepancy may be due to a lack of power to detect such a pattern. But this also suggests that the qualitative and quantitative effects of temperature on the strength of competition can vary depending on the trait affected by the competitive interactions. And this may also be the case for othe $r$ fundamental life history traits like reproduction and survival that were not studied here. Further theoretical work is required to explore the potential origins, and the evolutionary and ecological significance of such a between-trait variation of the shapes of the competition thermal reaction norms.
Direct effects of temperature on isolated individuals

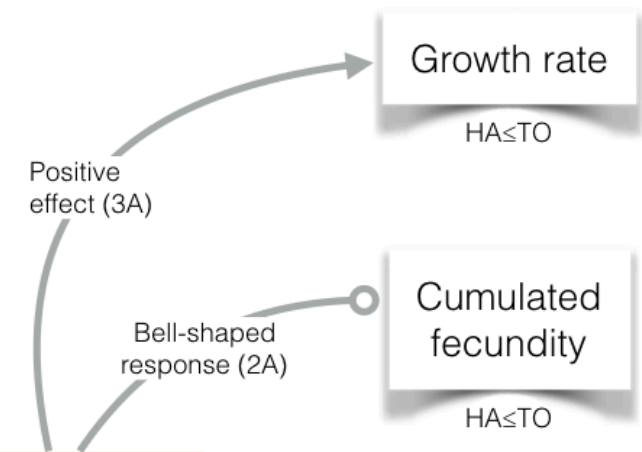

Temperature

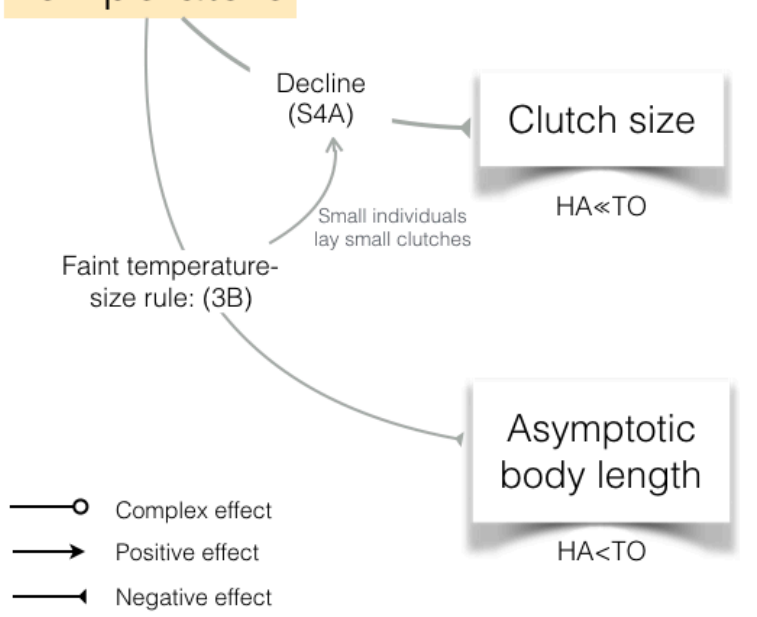

Joint effects of temperature and adult density in populations

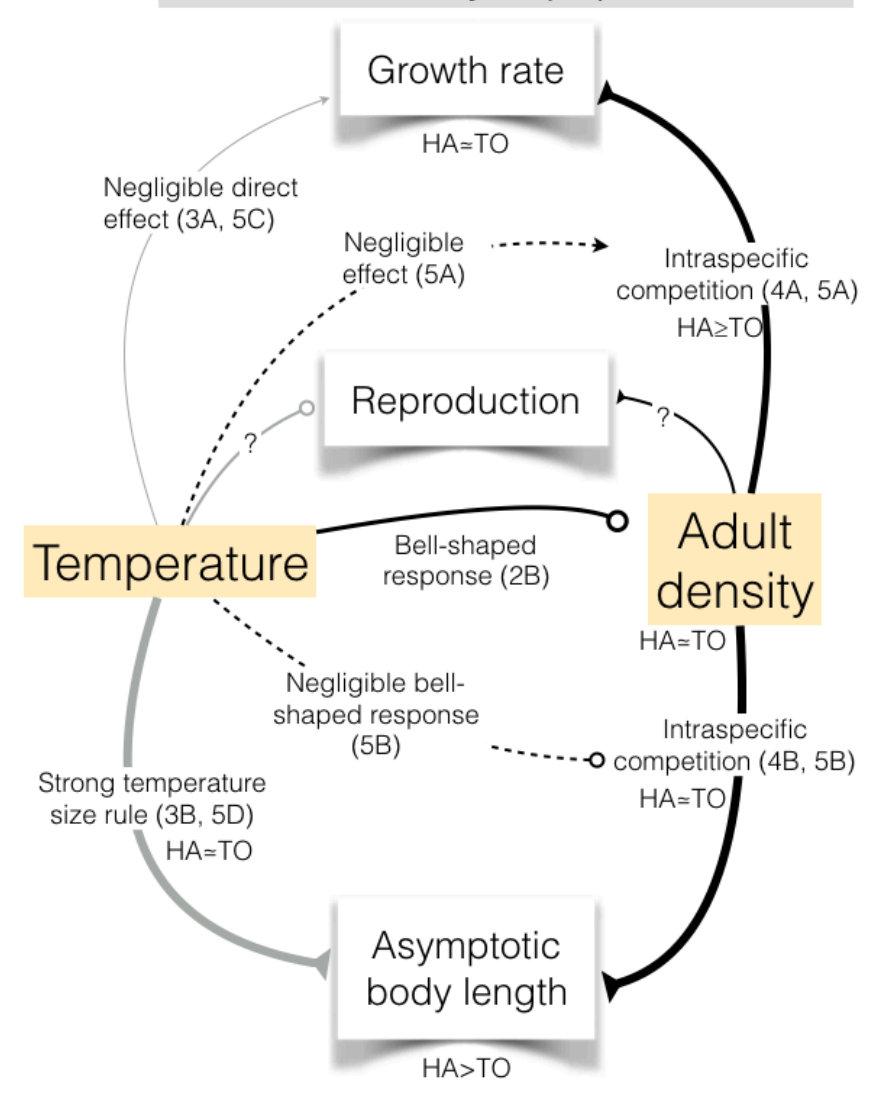

Figure 6: The direct and indirect effects of temperature on growth rates and asymptotic body lengths of isolated individuals (left) and of cohorts of individuals within populations (right). References in parenthesis point to figures. The line thickness underlines the relative strength of each effect. For example, adult density has a strong direct negative effect on both growth rate and asymptotic body length while temperature has a negligible direct effect on growth. Dotted lines represent the effects of temperature on the strength of intraspecific competition. Grey lines represent direct effects of temperature on life-history traits and black lines the effects linked with density in populations. Note that reproduction could not be measured in populations thus the probable effects of density and temperature on reproduction are mentioned with a question mark on the right side of the figure.

\section{Within-species genetic variation of thermal reactions norms}

Finally, our results reveal genetic differences between our clonal lineages in their mean trait values and in their plastic responses to both temperature and in- traspecific competition (Fig. 6). Isolated TO grow on average faster than $\mathrm{HA}$ in the hottest environments $\left(>=21^{\circ} \mathrm{C}\right)$ and reach a larger body length (Fig. 3). This difference is referred as a vertical or "faster-slower" shift: a change in the overall height of the thermal performance curves. This vertical shift is opposed to an 
horizontal or "hotter-cooler" shift: the variation in the location of the thermal maximum or in the position of the curve along the temperature axis (Kingsolver, 2009). While previous studies have described similar effects of temperature on Collembola growth rates (Birkemoe \& Leinaas, 2000; Driessen et al., 2007; Ellers, Mariën, Driessen, \& van Straalen, 2008), or on sizes at maturity (Stam, de Leemkule, \& Ernsting, 1996), we extend these results to asymptotic body lengths.

TO also produces on average larger clutches than $\mathrm{HA}$ (Fig. S4A), grows faster between $21^{\circ}$ and $26^{\circ} \mathrm{C}$ and reaches slightly larger asymptotic lengths over the whole temperature range (Fig. 6). These observations confirm that HA has a slow life history strategy compared to TO (Mallard et al., 2015; Tully \& Ferrière, 2008) which remains true under a broad temperature range. Interestingly, we show that the faster lineage also exhibit the stronger TSR response in population. A similar result has been shown in a multi-species comparison (Horne et al., 2015): multivoltine arthropods exhibit a steeper decrease in size with increasing temperature than univoltine ones. We also found that the optimal temperature is higher for HA than TO when looking at reproduction, but not when looking at growth. The significance of this discrepancy remains to be studied.

In populations, the genetic difference in growth rates vanishes and the genetic difference in asymptotic body lengths reverses. This reduction and reversal of genetic differences from one environment to another might result from genetic difference in resource acquisition, resource assimilation or from differences in resource allocation. Indeed, the lineages differ in their ability to invest into reproduction (Fig. 2A, B, (Tully \& Ferrière, 2008)). The fast lineage (TO) may require more nutritional resources to grow faster while reaching larger size and reproducing more than the slow one $(\mathrm{HA})$. In Daphnia, genetic diversity in resource allocation can generate differences in body size and age at maturity (Hoefnagel et al., 2018). When food becomes scarce in populations due to intraspecific competition, the gap between the resource requirement and its availability may become especially large for TO. The individuals would then be constrained to reduce the resource allocated to growth to favour reproduction which may result in the comparatively large number of juveniles observed in these populations (Fig. S4B). This lineage may also have an increased resource intake (which is advantageous when the resource is unlimited) but a lower assimilation efficiency, resulting in smaller average sizes in populations where the resources become limiting.

Together, our observations support the idea of genetic variation in the fraction of resource allocated to reproduction and growth (De Jong \& van Noordwijk, 1992). Further work is needed to study whether this genetic variation in resource allocation is linked to a putative variation in resource acquisition and assimilation efficiency and more specifically to examine whether it is advantageous for organism with relatively low assimilation efficiency (TO vs. HA or large vs. small individuals) to slow growth and invest more in reproduction when resources become scarce.

We also found the thermal reaction norms of competition on size were very similar between the two clones, while the ones of competition on growth rate differed significantly - the strength of competition on growth being higher for HA than for TO over the whole thermal range. This adds another level of potential complexity: the within-species genetic variability of the strength of competition can also vary from one trait to another.

\section{Conclusion}

To conclude, our study shows that the strength of competition vary on different life history traits and that the trait most affected by competition will change as the thermal environment and population dynamics change. We also provide empirical evidence for withinspecies genetic variation in thermal reaction norms and in plastic responses to intraspecific competition. By providing a quantitative analysis of the way growth rates and asymptotic lengths change according to temperature and density in a population context, we stress the need for untangling the complex interactions between environment and demography. Our results reinforce the idea that the TSR response of ectotherms can be modulated by biotic and abiotic stressors when studied in non-optimal laboratory experiments.

\section{Data accessibility}

Data deposited in the Dryad Digital Repository: https:/ /doi.org/10.5061/dryad.9w0vt4bb6, (Tully, 2019) 


\section{Tables}

Table 1: The two models of this table have been done to study whether indirect effects of temperature (via competition) alter patterns seen at the individual level. Model A (growth rate) is associated with the Figure $3 \mathrm{~A}$ and model $\mathrm{B}$ (asymptotic length) with Figure 3B. In both models, the variable lineage has two levels (HA, TO), temperature has 5 levels $\left(29^{\circ} \mathrm{C}\right.$ is not included since we have no population at this temperature) and the variable competition is used to tell the difference between measurements made on isolated individuals with the ones made on populations. Non-significant interactions that have been dropped from initial full models are shown in italics. Effects and their interactions are tested with likelihood ratio tests using a type 3 anova (Anova function from the car package). Parameters of full models A and B are provided in Table S3.

\begin{tabular}{|c|c|c|c|}
\hline Factors & Likelihood ratio Chi-square & Df & P (>Chisq) \\
\hline \multicolumn{4}{|l|}{ (A) Growth rate } \\
\hline Lineage (HA/TO) & 2.3 & 1 & 0.13 \\
\hline Temperature (factor) & 35.9 & 4 & $<0.001$ \\
\hline Competition (isolated/population) & 8.5 & 1 & 0.003 \\
\hline Temperature ${ }^{\star}$ Competition & 50.6 & 4 & $<0.001$ \\
\hline Lineage ${ }^{\star}$ Competition & 0.76 & 1 & 0.38 \\
\hline Lineage ${ }^{\star}$ Temperature & 8.1 & 4 & 0.09 \\
\hline Temperature ${ }^{*}$ Lineage ${ }^{*}$ Competition & 16.1 & 4 & 0.0028 \\
\hline \multicolumn{4}{|l|}{ Growth rate for HA } \\
\hline Temperature (factor) & 27.2 & 4 & $<0.001$ \\
\hline Competition (isolated > population) & 6.5 & 1 & 0.011 \\
\hline Temperature ${ }^{\star}$ Competition & 38.3 & 4 & $<0.001$ \\
\hline \multicolumn{4}{|l|}{ Growth rate for TO } \\
\hline Temperature (factor) & 17.2 & A & 0.002 \\
\hline Competition (isolated $>$ population) & 12.4 & 1 & $<0.001$ \\
\hline Temperature*Competition & 237.1 & 4 & $<0.001$ \\
\hline \multicolumn{4}{|l|}{ (B) Asymptotic body length } \\
\hline Lineage (HA/TO) & 9.4 & 1 & $<0.001$ \\
\hline Temperature (factor) & 99.4 & 4 & $<0.001$ \\
\hline Competition (isolated/population) & 3.1 & 1 & 0.09 \\
\hline Temperature ${ }^{\star}$ Competition & 35.0 & 4 & $<0.001$ \\
\hline Lineage ${ }^{\star}$ Competition & 22.2 & 1 & $<0.001$ \\
\hline Lineage ${ }^{\star}$ Temperature & 19.6 & 4 & $<0.001$ \\
\hline Temperature* Lineage ${ }^{*}$ Competition & 8.6 & 4 & 0.07 \\
\hline \multicolumn{4}{|l|}{ Asymptotic body length for HA } \\
\hline Temperature (factor) & 78.3 & 4 & $<0.001$ \\
\hline Competition (isolated population) & 2.1 & 1 & 0.14 \\
\hline Temperature*Competition & 17.8 & 4 & 0.001 \\
\hline \multicolumn{4}{|l|}{ Asymptotic body length for TO } \\
\hline Temperature (factor) & 37.7 & 4 & $<0.001$ \\
\hline Competition (isolated > population) & 6.2 & 1 & 0.012 \\
\hline Temperature*Competition & 32.8 & 4 & $<0.001$ \\
\hline
\end{tabular}


From individuals to populations: How intraspecific competition shapes thermal reaction norms

Table 2: This table represents the best selected linear models that we used to study effects of lineage (HA and TO) and temperature (as a factor) on growth rate (A, B, Figure $3 A$ ) and asymptotic size (C, D, Figure 3B) measured either on isolated individuals (A, C, Figure 3 open symbols and thin line) or in populations (B, D, Figure 3, filled symbols and thick lines). Small and large HA adults at $21^{\circ} \mathrm{C}$ are taken into account in the model. Interactions that have been dropped from initial full models are italicized. Effects and their interactions are tested with likelihood ratio tests using a type 3 anova (Anova function from the car package). We also report the effects of temperature tested independently for the two clones for models $A$ and $D$ since the interaction between lineage and temperature was significant.

\begin{tabular}{|c|c|c|c|}
\hline Factors & $\begin{array}{c}\text { Likelihood ratio Chi- } \\
\text { square }\end{array}$ & Df & $P(>$ Chisq) \\
\hline \multicolumn{4}{|l|}{ (A) Growth rate of isolated individuals } \\
\hline Lineage (HA/TO) & 0.00 & 1 & 0.99 \\
\hline Temperature (factor) & 116.6 & 5 & $<0.001$ \\
\hline Lineage*Temperature $\left(6-16^{\circ}: \mathrm{HA}=\mathrm{TO} ; 21-29^{\circ}: \mathrm{HA}<\mathrm{TO}\right)$ & 11.9 & 5 & 0.035 \\
\hline Temperature (HA only) & 102 & 5 & $<0.001$ \\
\hline Temperature (TO only) & 322 & 5 & $<0.001$ \\
\hline \multicolumn{4}{|l|}{ (B) Growth rate in populations } \\
\hline Lineage $(\mathrm{HA}=\mathrm{TO})$ & 2.3 & 1 & 0.13 \\
\hline Temperature (factor) & 35.8 & 4 & $<0.001$ \\
\hline Lineage ${ }^{*}$ Temperature & 8.08 & 4 & 0.089 \\
\hline \multicolumn{4}{|l|}{ (C) Asymptotic body length of isolated individuals } \\
\hline Lineage $(\mathrm{HA}<\mathrm{TO})$ & 8.0 & 1 & 0.0047 \\
\hline Temperature (factor) & 1105 & 5 & $<0.001$ \\
\hline Lineage ${ }^{\star}$ Temperature & 4.9 & 5 & 0.42 \\
\hline \multicolumn{4}{|l|}{ (D) Asymptotic body length of cohorts in populations } \\
\hline Lineage (HA>TO) & 7.8 & 1 & 0.005 \\
\hline Temperature (factor) & 91 & 4 & $<0.001$ \\
\hline Lineage*Temperature & 23.2 & 4 & $<0.001$ \\
\hline Temperature (HA only) & 69.0 & 4 & $<0.001$ \\
\hline Temperature (TO only) & 30.6 & 4 & $<0.001$ \\
\hline
\end{tabular}




\title{
Supporting Information
}

\author{
Supporting methods
}

\section{(i) The Collembola Folsomia candida as a model organism}

The Collembola Folsomia candida is a broadly distributed throughout the world. It is found in habitats such as decaying litter, rotting wood or in caves. It is easy to maintain in the laboratory, and can be bred in isolation or in populations in simplified microcosms with a fine control of temperature, humidity, food provisioning and density (Fountain \& Hopkin, 2005). This species is known for its highly flexible phenotypic adjustments when experiencing a sudden change in density or resource abundance (Tully \& Ferrière, 2008). As a parthenogenetic species, multiple individuals sharing the same genotype can easily be bred in different environmental conditions. We worked with two distinct genetic clonal lineages (labelled respectively TO and HA) with contrasted ecological history and biodemographic strategies (Tully, D’Haese, Richard, \& Ferriere, 2006; Tully \& Ferrière, 2008; Tully \& Lambert, 2011; Mallard et al., 2015): at $21^{\circ} \mathrm{C}$ at low density, HA individuals have on average a lower reproductive potential and a lower basal mortality than TO individuals and they reach a higher body length. But the ecological natural conditions in which these lineages are adapted are not known.

\section{(ii) Rearing of isolated individuals and of populations at different}

\section{temperatures}

Both isolated individuals and populations were kept in standard rearing boxes made of polyethylene vials (diameter $52 \mathrm{~mm}$, height $65 \mathrm{~mm}$ ) filled with a $30 \mathrm{~mm}$ layer of plaster of Paris mixed with $600 \mathrm{~mL}$ of Pébéo graphic $\AA$ Chinese ink to increase visual detectability of light individuals against the dark background (Tully \& Ferrière, 2008). Rearing boxes were kept in incubators (Velp FOC 225E, temperature controlled $\pm 0.5^{\circ} \mathrm{C}$ ) at six temperatures $\left(6^{\circ}\right.$, $11^{\circ}, 16^{\circ}, 21^{\circ}, 26^{\circ}$ and $\left.29^{\circ} \mathrm{C}\right)$ at constant humidity $(\sim 100 \%)$ and in darkness. Food was provided in the form of small pellets of a mixture of dried yeast and agar in standardised concentration and volume $(5000 \mathrm{~mL}$ water +80 $\mathrm{mg}$ agar+800 $\mathrm{mg}$ dried yeast, to produce pellets of $15 \mu \mathrm{L}$ ).

Isolated individuals came from new-borns that were isolated immediately after hatching and fed ad libitum during their whole life. We studied between 12 and 20 individuals per lineage and temperature (mean 15.4).

Populations were founded with 5 to 10 adults and were kept at the same temperatures as those for isolated individuals (Fig. 1). We were not able to maintain viable populations at $29^{\circ} \mathrm{C}$ because at this temperature the collembola do not reproduce (Fig. 2A). Between four and twelve populations were started for each lineage at each temperature (Fig. S2).

\section{(iii) Measuring densities of large and small individuals.}

We used the option region = TRUE of the STdiag.measure function to extract a region of the plot and get from it the number of individuals and the length of each individual during the periods of measurements. More specifically, for measurements of asymptotic body lengths we estimated the mean density of large individuals (which we called "adults") and small ones (also called "juveniles") at the time of each measurement as the mean density during a five weeks period which includes the week of the measurement, three weeks before and the week after the measurement (Fig. 1, Fig. 2B). We used five weeks periods to get average measurements of the density integrating fluctuations of density that could occur during the period of stabilization of the mean body length of the studied cohorts. For growth rate measurements, the density of large and small collembola were estimated as the mean densities over the period of time on which the growth rate has been estimated.

We used the number of large individuals (on a log scale) to quantify the relationship between temperature and "adult" density (Fig. 2B) and to further measure the strength of competition by quantifying the dependence of growth rate and asymptotic length to adult density (Fig. 4). We used the logarithm of adult density as a proxy of the population state since adults represent on average $90 \%$ of the total "biosurface" (total surface of collembola estimated with our pictures) in our populations and since we knew from previous experiments that large individuals play a central role in the density dependent effects by outcompeting small individuals in resource acquisition (Le Bourlot, 2014; Le Bourlot et al., 2014).

Note that when two modes of large individuals could be identified (HA populations at $21^{\circ} \mathrm{C}$, Fig. S2), we only took into account the number of very large individuals $(>1.5 \mathrm{~mm}$ ) because we know from the previous experiments mentioned above that the large collembola dominates not only the juveniles but also the smaller adults. 
From individuals to populations: How intraspecific competition shapes thermal reaction norms

\section{populations}

\section{(iv) Measuring the mean growth rates and asymptotic body lengths in}

Cohort growth rates. To measure the growth rates of the cohorts on the structure-time diagrams (Fig. S2), we adjusted a strait line rather than a growth curve because many cohorts that are well distinguishable during their period of maximum growth are less well distinguishable before and after this period especially when they merge with other cohorts.

Asymptotic body length. We found no other reliable way to automatically measure the cohorts' asymptotic body lengths due to the complexity of the structure-time diagrams, especially when several cohorts fuse or when several modes of large collembola coexist (See the example in Fig. 1 and some populations such as TO_21_r2 in Fig. 2). 


\section{Supporting figures}

Figure S1: Comparing methods to measure growth rates. To verify that the method used to measure the growth rates in populations provides estimates that we can safely and reliably compare to the ones made on isolated individuals, we have studied in details 14 cohorts than can be easily identified on the plots and we have extracted about 17 points on each of these cohort's growth trajectories. We used this dataset to compare growth rates estimated by eye on these cohorts with growth rates estimated by fitting a parametric growth curve. More specifically, we fit smoothed spline growth curves on these 14 cohorts, using the gcFitSpline function from the grofit package (Type=Gompertz). These fits were done recursively with different values of the smooth.gc parameter (between 0 and 1) and for each of these values, we measured the R-squared and the slope of a regression between the growth parameters estimated by eye and the growth parameters estimated from the smoothed splines. The figure shows how varying the smooth parameter of the spline curves modifies the quality of the regression between the two types of measurements. The red curve shows the R-squared for different values of the smooth parameters. The blue curve quantifies how far the regression slope is from a slope of one. The R-squared reach values higher than 0.95 for smooth.gc parameter above 0.45 and a smooth.gc parameter of 0.57 minimizes the difference between the estimation of the slope (0.99) and one. Thus, to minimize potential bias between the two methods, we choose to use a smooth parameter of 0.57 to fit the growth curves of the isolated individuals.

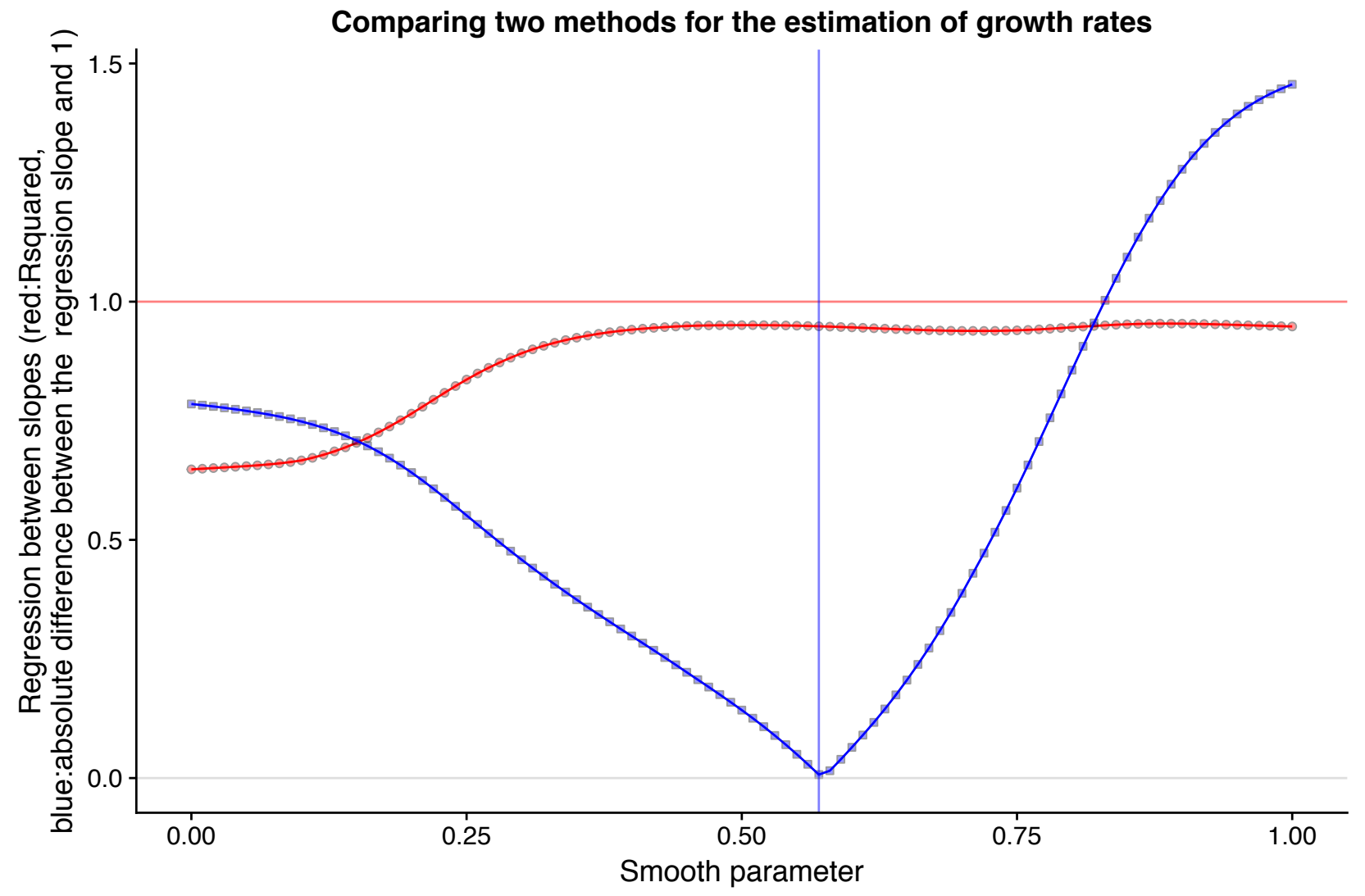


Figure S2: Structure time diagrams of 56 populations from two clonal lineages of Collembola (HA on the left side and TO on the right side) raised at five different temperatures $\left(6,11,16,21\right.$ and $\left.26^{\circ} \mathrm{C}\right)$. The population labelled «HA_06_r1 » for example is the first population (replicate 1) of $\mathrm{HA}$ individuals raised at $6^{\circ} \mathrm{C}$. Some populations became extinct and their dynamics are not plotted (ex. HA_11_r3). These diagrams display the temporal dynamics of the populations' size-structure: for each time (xaxis, number of days) and size class (y-axis, body length in $\mathrm{mm}$ ) coordinate, a colour rectangle is plotted whose hue refers to the number of individuals (on a log scale, scale on the right side of each plot). We used these diagrams to estimates the growth rate and asymptotic body length of cohorts. All these measurements were done using the function STdiag.measure from the $\mathrm{R}$ library STdiag that we specifically developed for this purpose (Le Bourlot V et al., 2015). This function is designed to interact with the structure-time diagram in order to obtain some quantitative measurements such as growth rate or average length of a group of individuals by clicking directly on the diagram. Note that a difficulty comes when measuring the asymptotic length from the remarkable plasticity of the springtails. They can resume growth or even shrink when the environmental conditions change (the density and structure of the populations change). To deal with this, we chose to focus on the mean length reached by a cohort right after it has stopped or significantly slowed down its growth even if the cohort can resume growth after a while when the population density changes for instance.

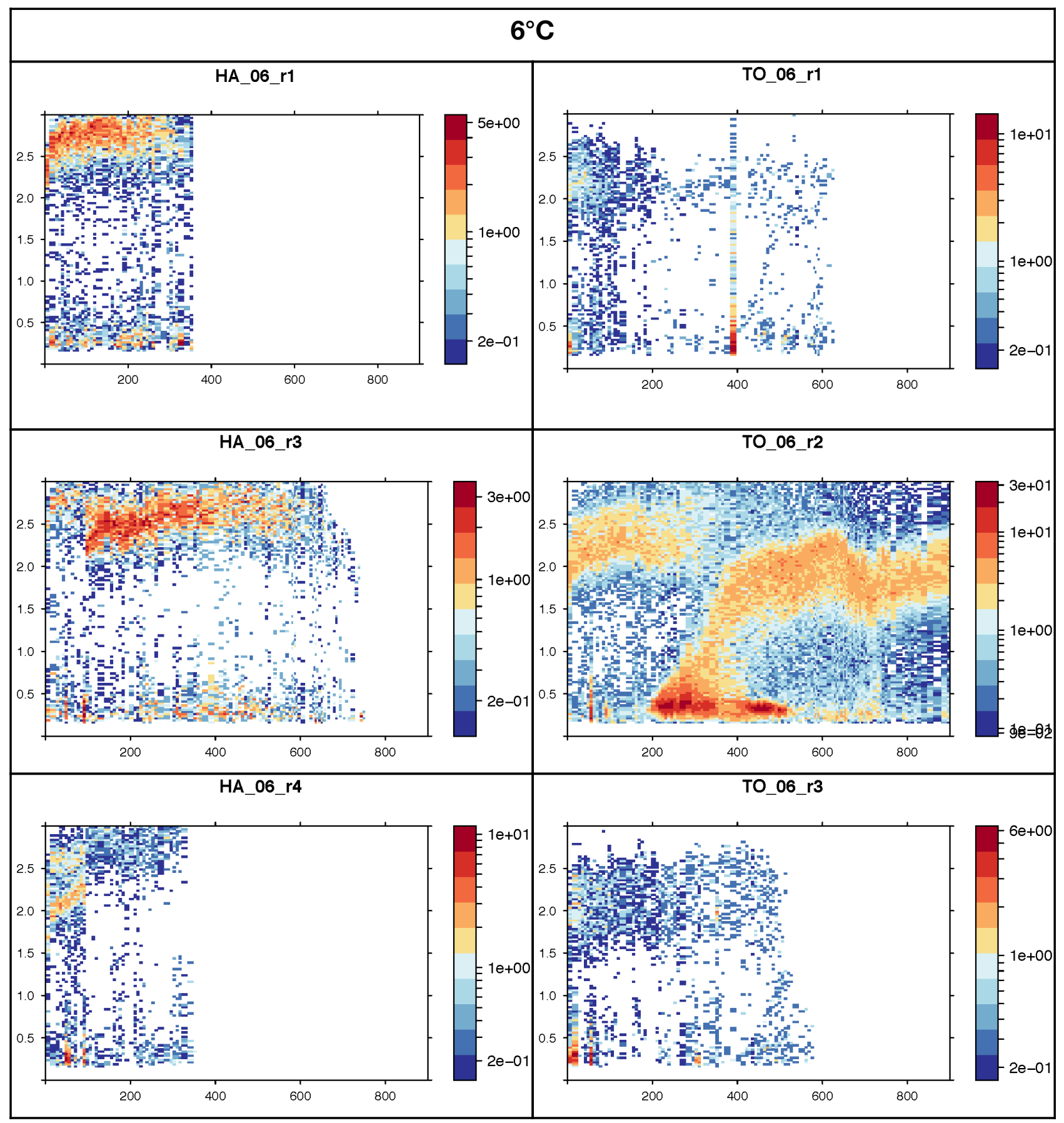


From individuals to populations: How intraspecific competition shapes thermal reaction norms

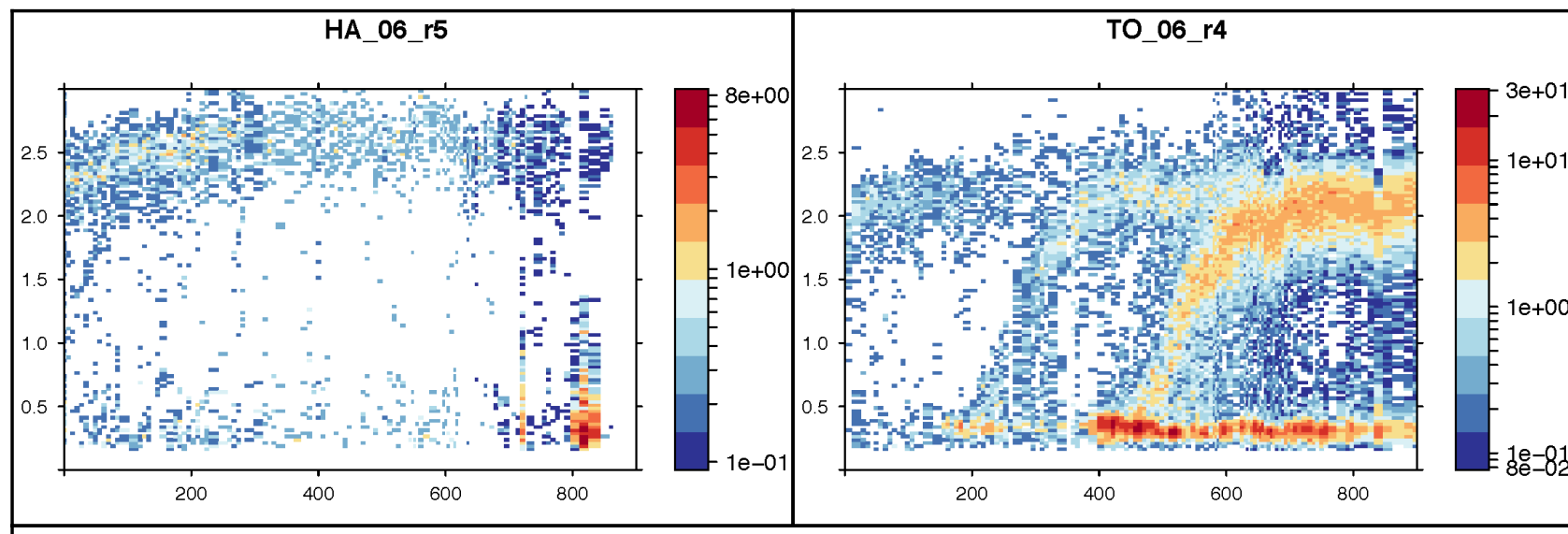

$11^{\circ} \mathrm{C}$

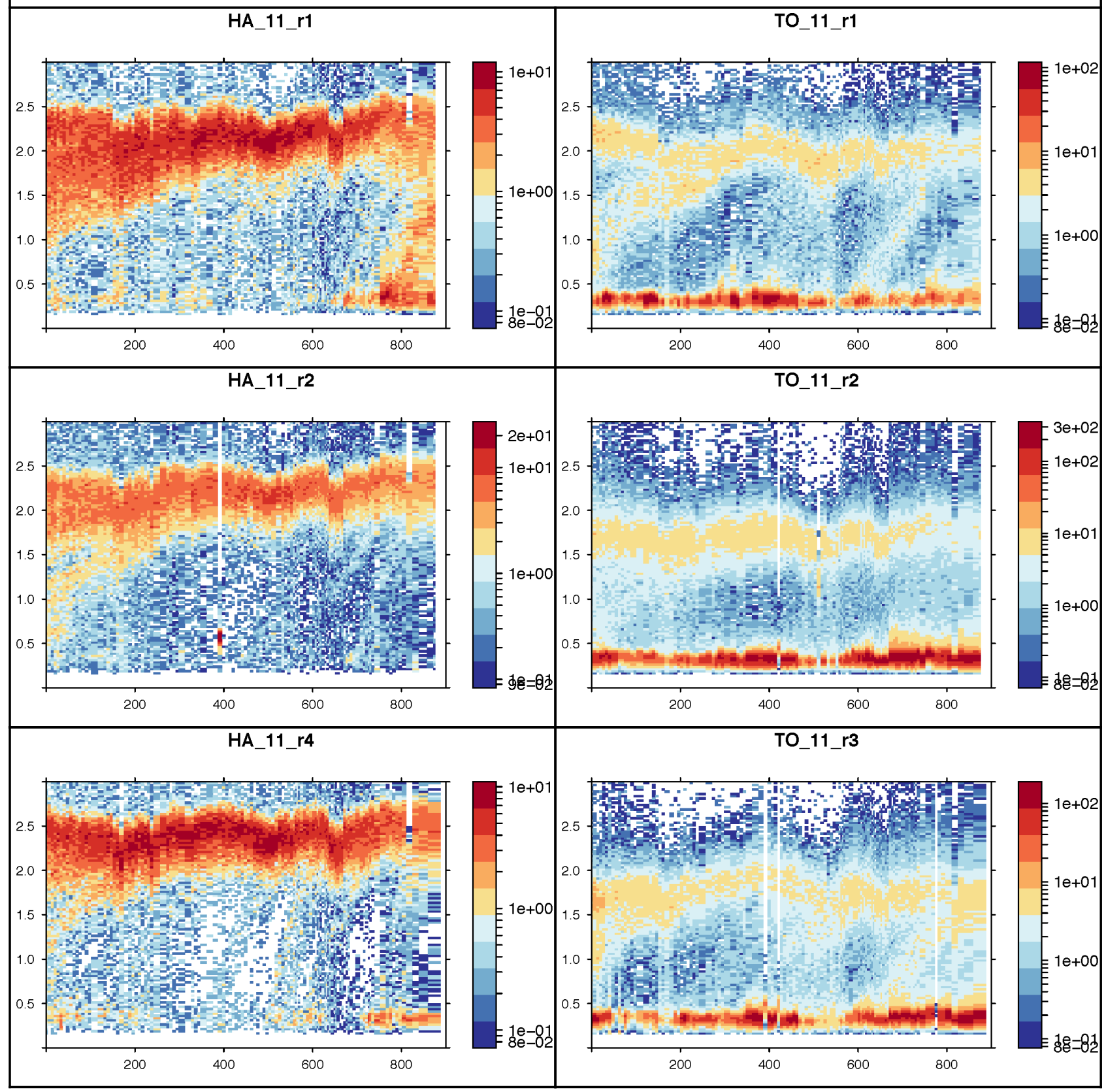


From individuals to populations: How intraspecific competition shapes thermal reaction norms

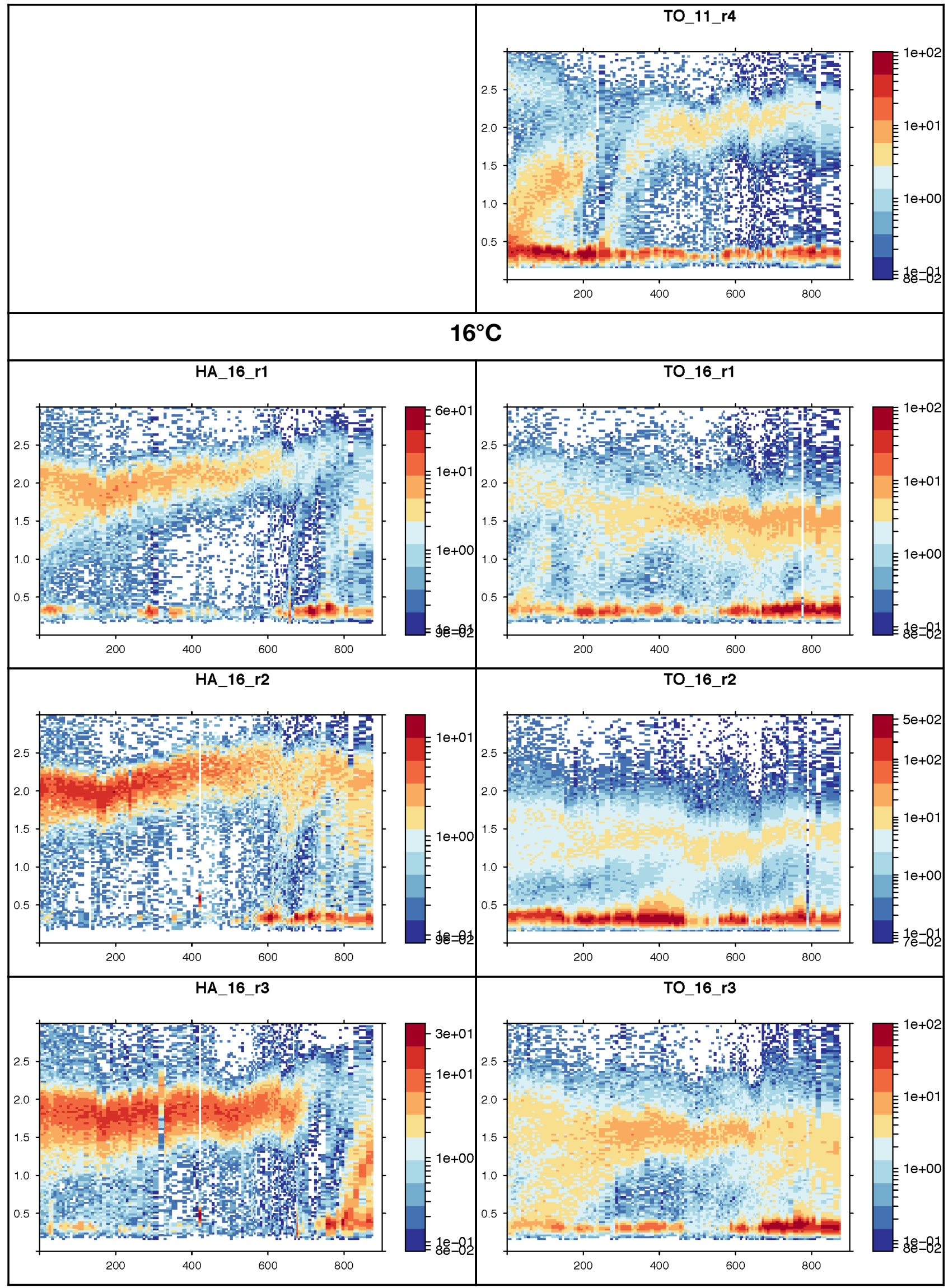


From individuals to populations: How intraspecific competition shapes thermal reaction norms

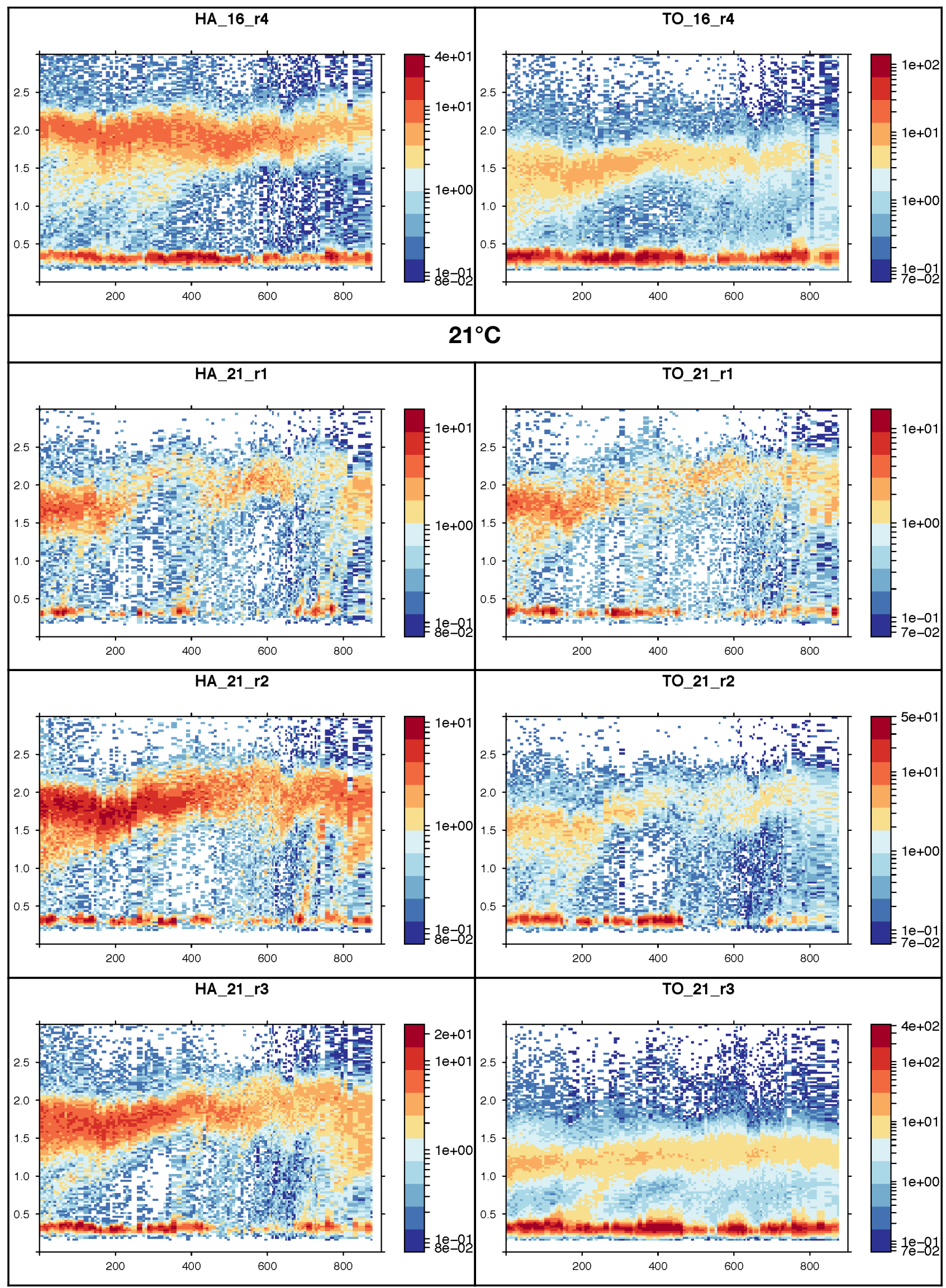


From individuals to populations: How intraspecific competition shapes thermal reaction norms

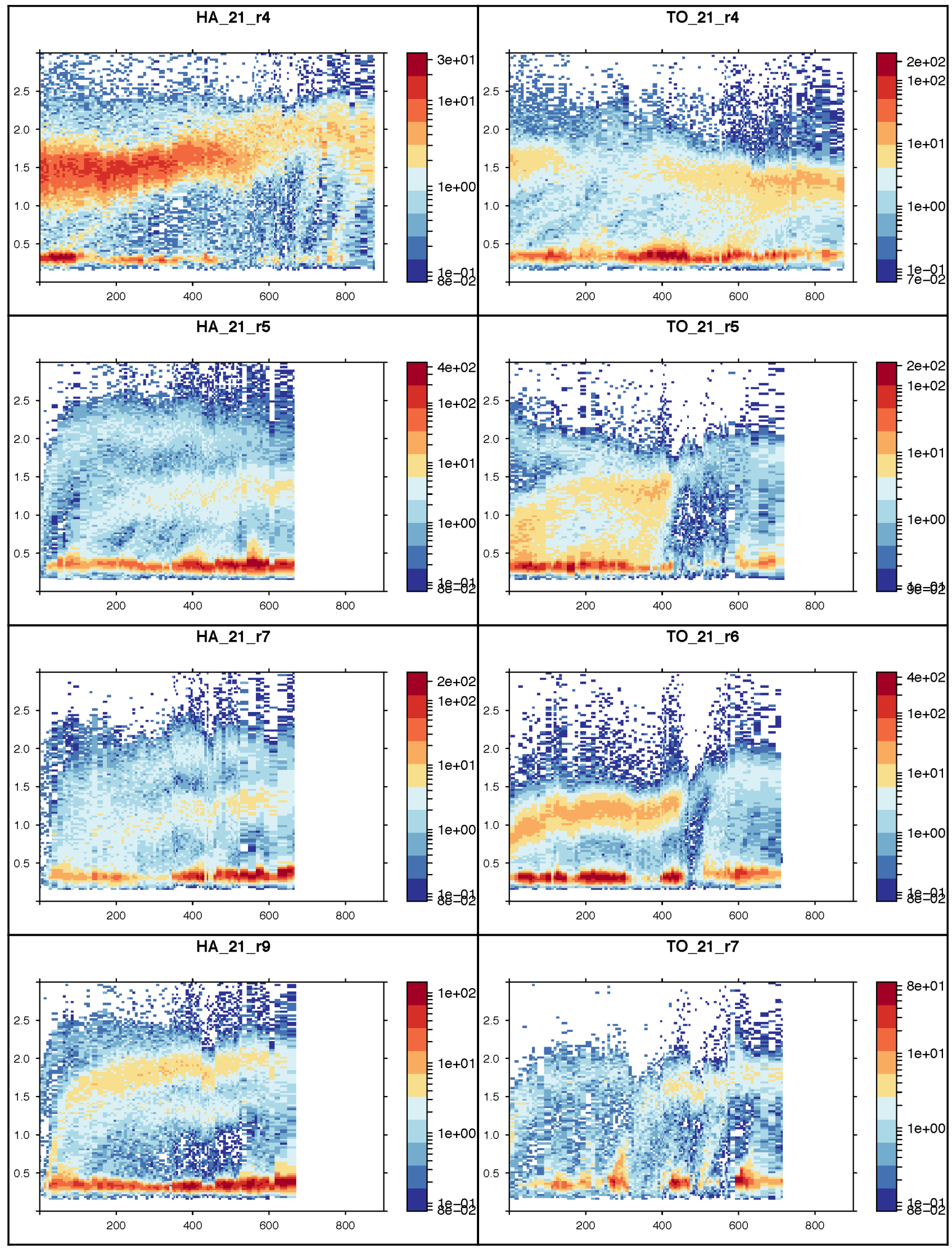


From individuals to populations: How intraspecific competition shapes thermal reaction norms

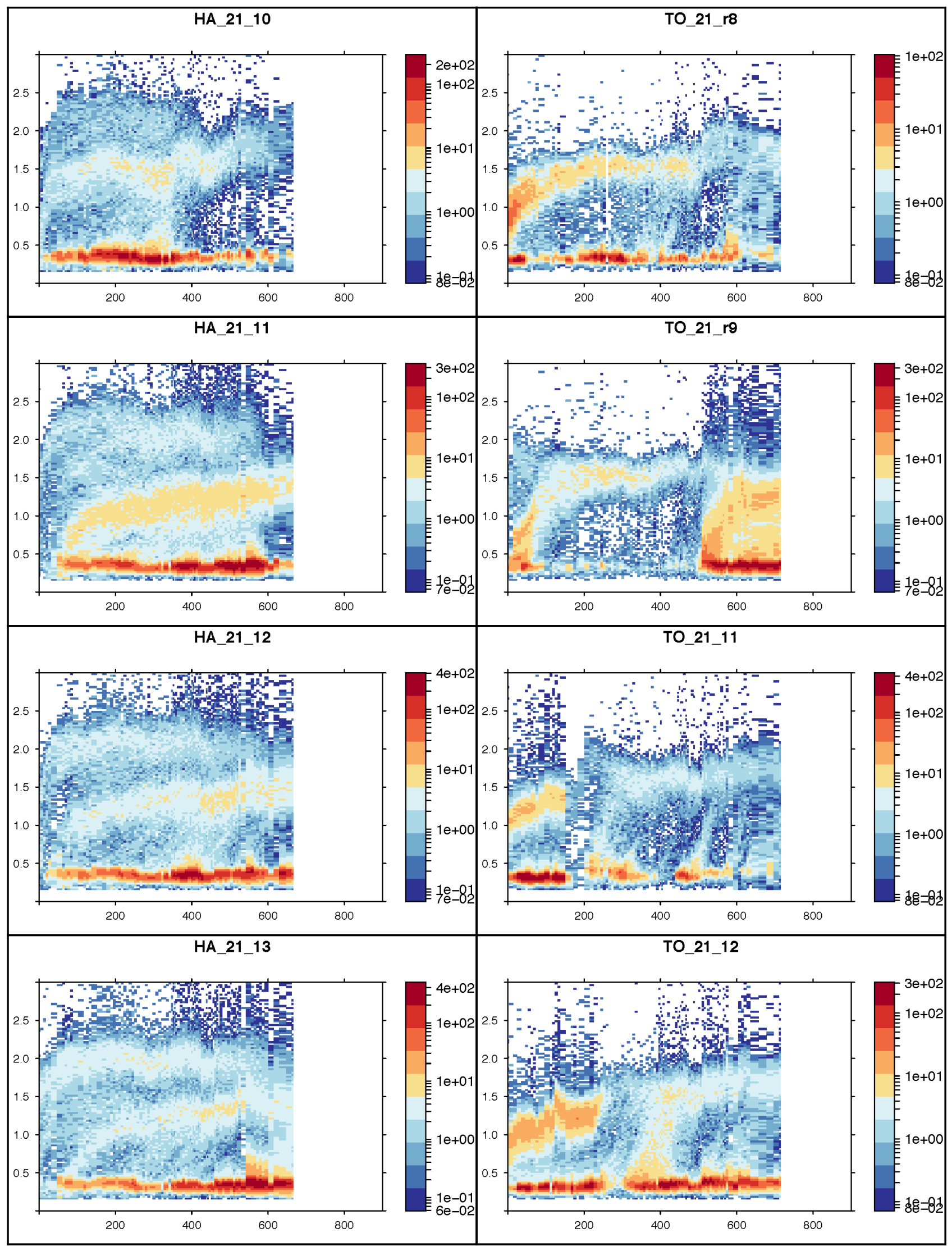


From individuals to populations: How intraspecific competition shapes thermal reaction norms

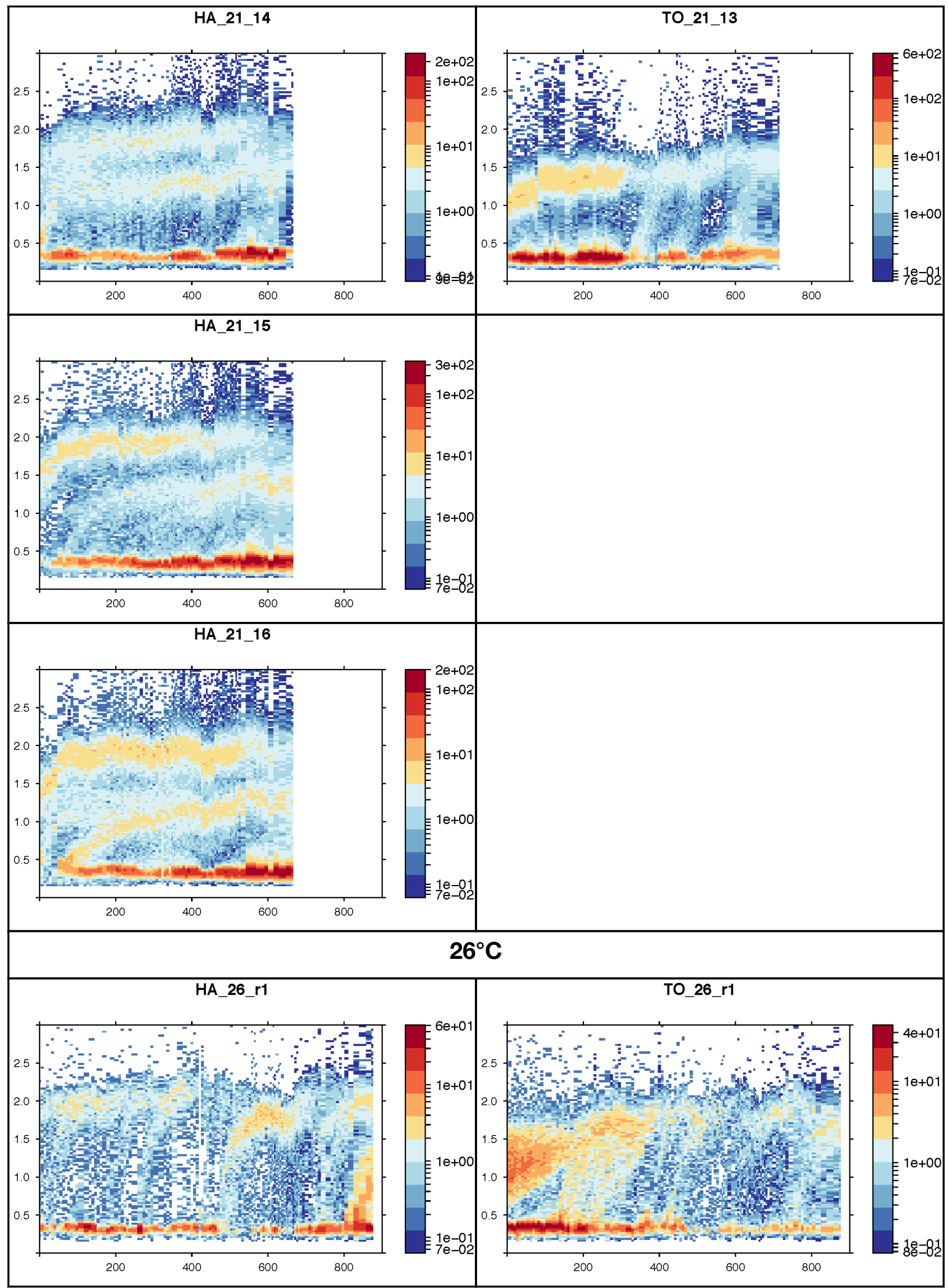


From individuals to populations: How intraspecific competition shapes thermal reaction norms

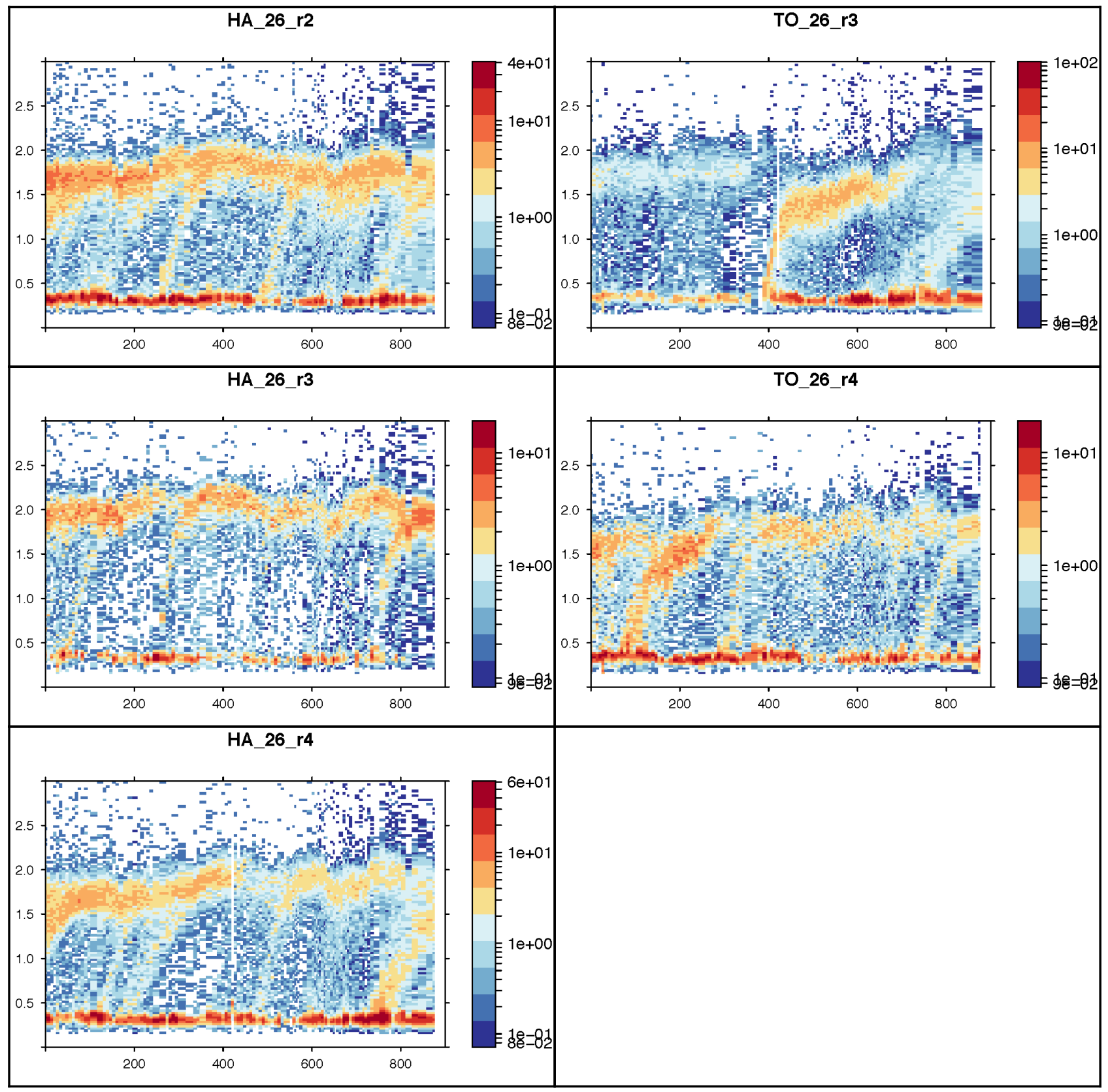


Figure S3: Two populations where different cohorts of juvenile recruiting in adults are visible. Black segments are fitted on cohorts that are sufficiently contrasted to be used to do the growth measurements. Red arrows point toward other cohorts that are less distinguishable and that were not used to estimate their growth rates. The black dots show the measurements of asymptotic body lengths.

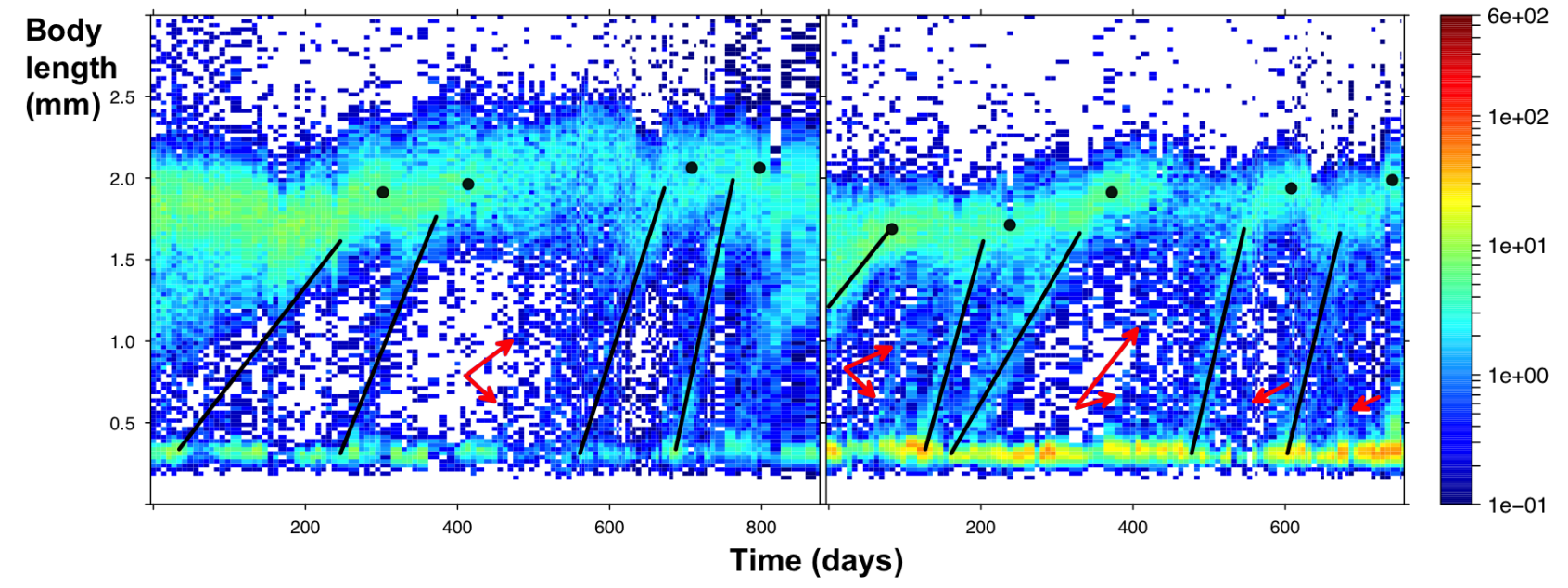

Figure S4: The effects of temperature on the clutch size produced by isolated individuals (A) and on juvenile density in populations (B) for lineages HA (open circle) and TO (grey diamonds). Panel A presents mean clutch sizes (mean numbers of eggs per clutch measured on 336 clutches, +/- 95\% confidence interval) as a function of temperature. The TO lineage lay on average larger clutches than HA. The juvenile density in populations is plotted as a function of temperature on panel B (see methods for details). On average, there are more juveniles in TO populations than in HA ones.

A Clutch size

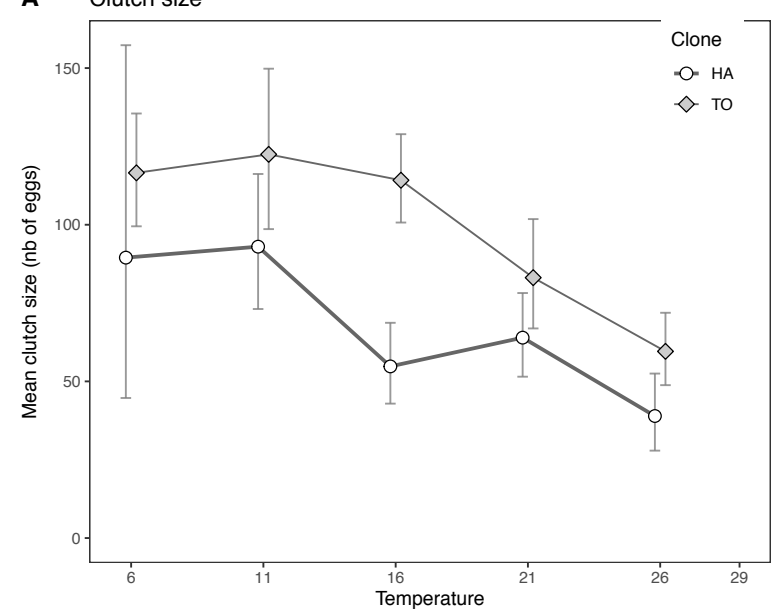

B Juvenile density

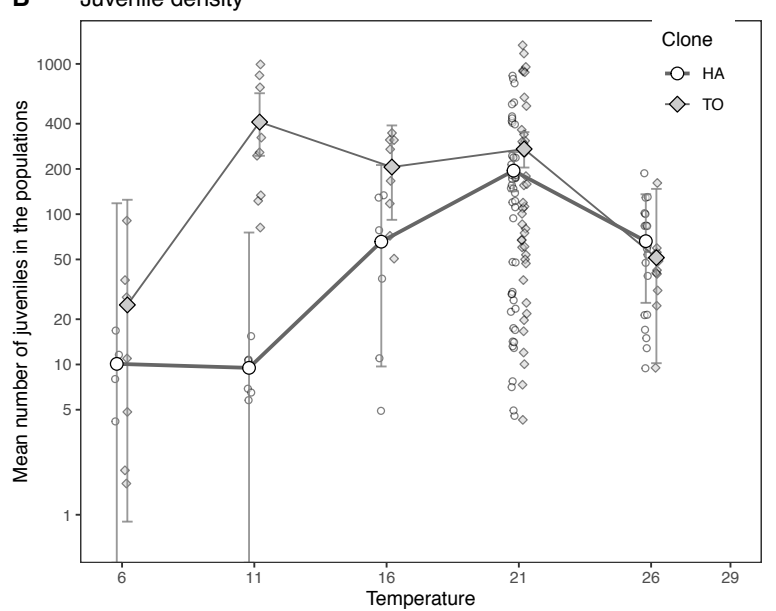

Figure S5: Relation between the adult biosurface (sum of the surface of all the adults in a box in mm2) and the adult density (number of adults per container) for the two lineages and at the five temperatures. For the same adult density, the biosurface of $\mathrm{HA}$ is higher than TO because on average in populations adults HA are larger than TO.

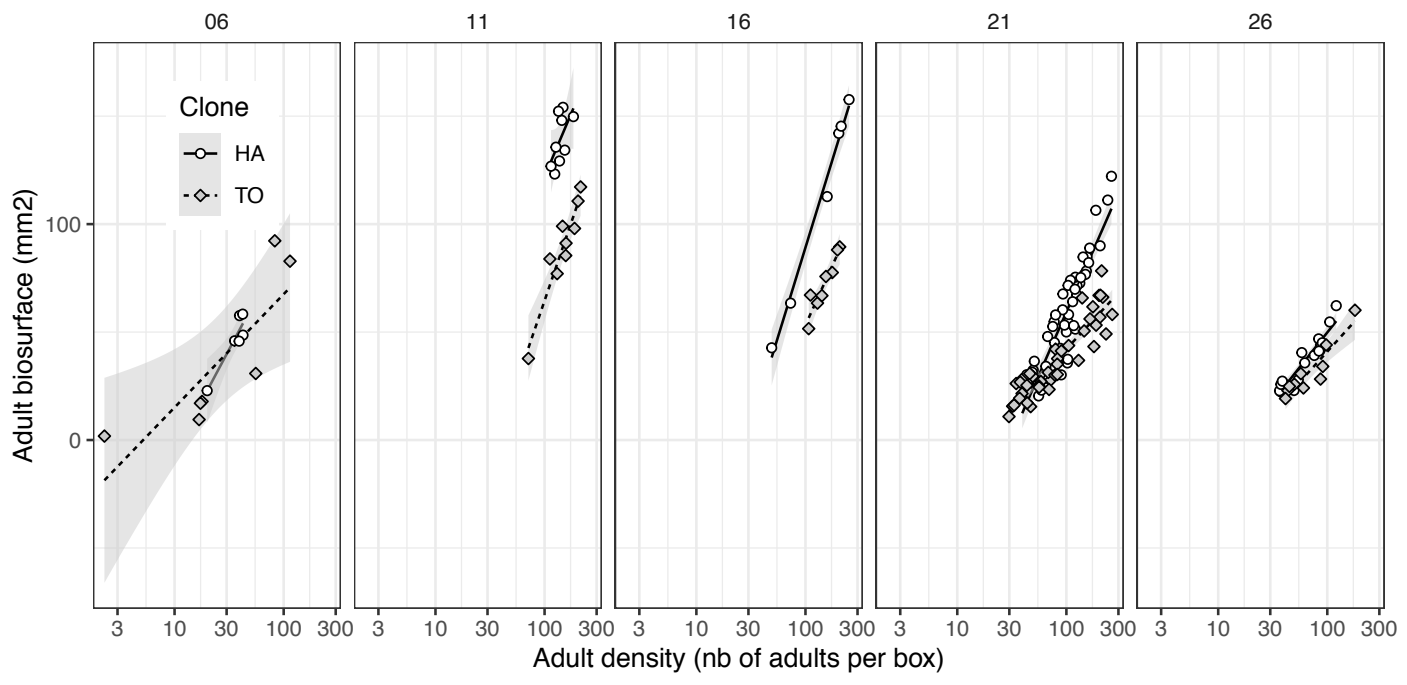


Figure S6: Trimodal body length distributions observed in some of $\mathrm{HA}$ populations raised at $21^{\circ} \mathrm{C}$ when the mean asymptotic size attained by some cohorts was measured (Figure S1). A kernel density estimation (red curve) has been fitted to the raw distribution (black histogram). The extremes of these red curves were used to automatically split each size distribution into three size classes separated here by black vertical lines.
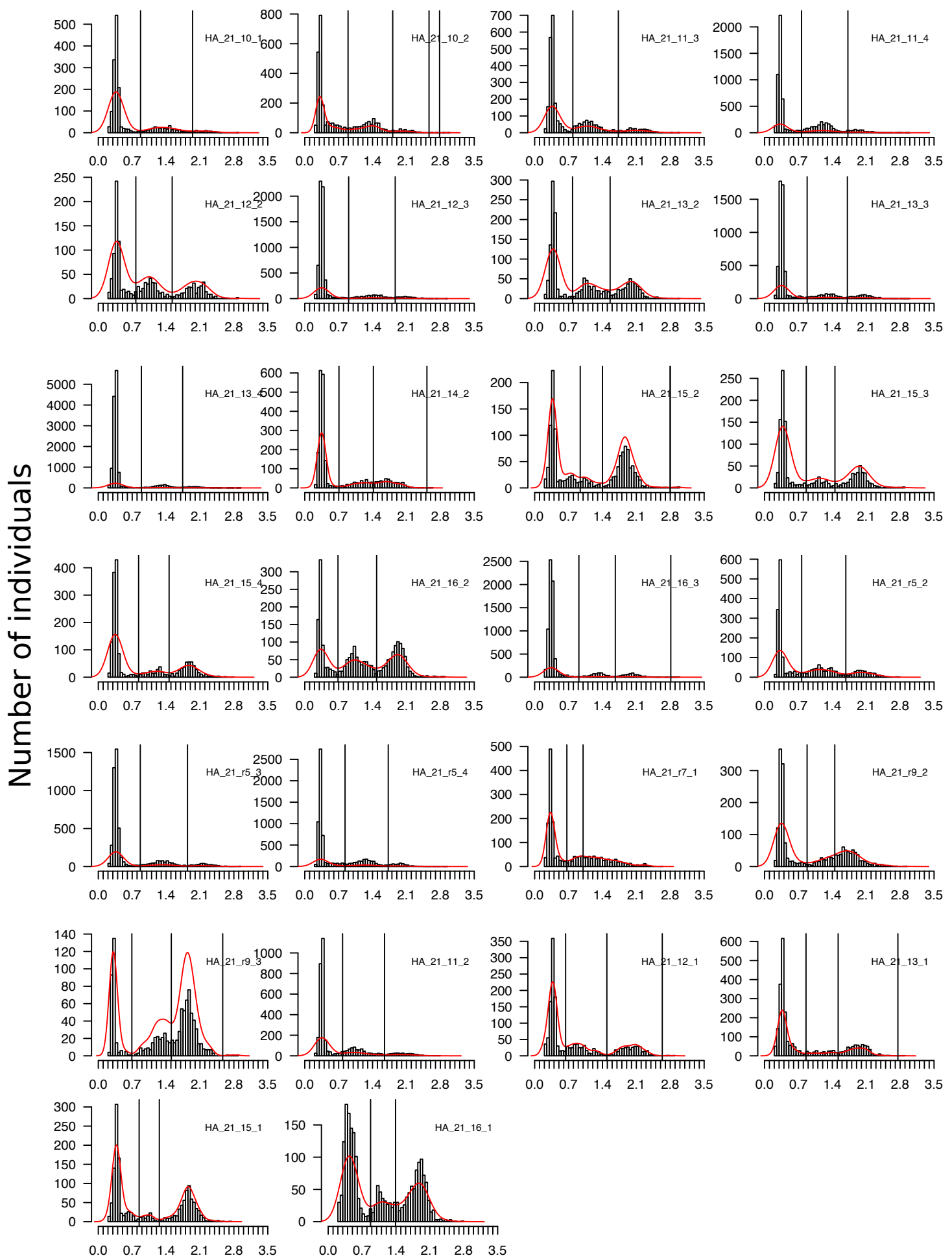

Body length $(\mathrm{mm})$ 
Figure S7: The visual display of the joint effect of temperature and density on growth rates and asymptotic body lengths using data measured on isolated individuals (Adult density of 1) and in populations. Panel A shows the positive effect of warming on growth rate and the additive negative effect of density (competition) on growth. One can also see that above a certain density, the isoclines become more or less horizontal. This means that, as the density increases, the temperature has less and less effects on the growth rates, the main variable that limits growth being the competition. Panel B shows that for the very low densities, the asymptotic length decreases with increasing temperature for both lineages. For TO, the interspecific competition has a negative effect on asymptotic length with an additive effect of temperature that remains on almost the whole range of conditions explored. For HA, the density has first a positive effect on asymptotic length: when the adult density increases between 1 and about 50 adults per container, the collembola tend to reach a longer asymptotic body length. But when the density continues to increase, its effect becomes negative (the isoclines are bended and their slopes change, B).

\section{A Growth rate (mm/day)}

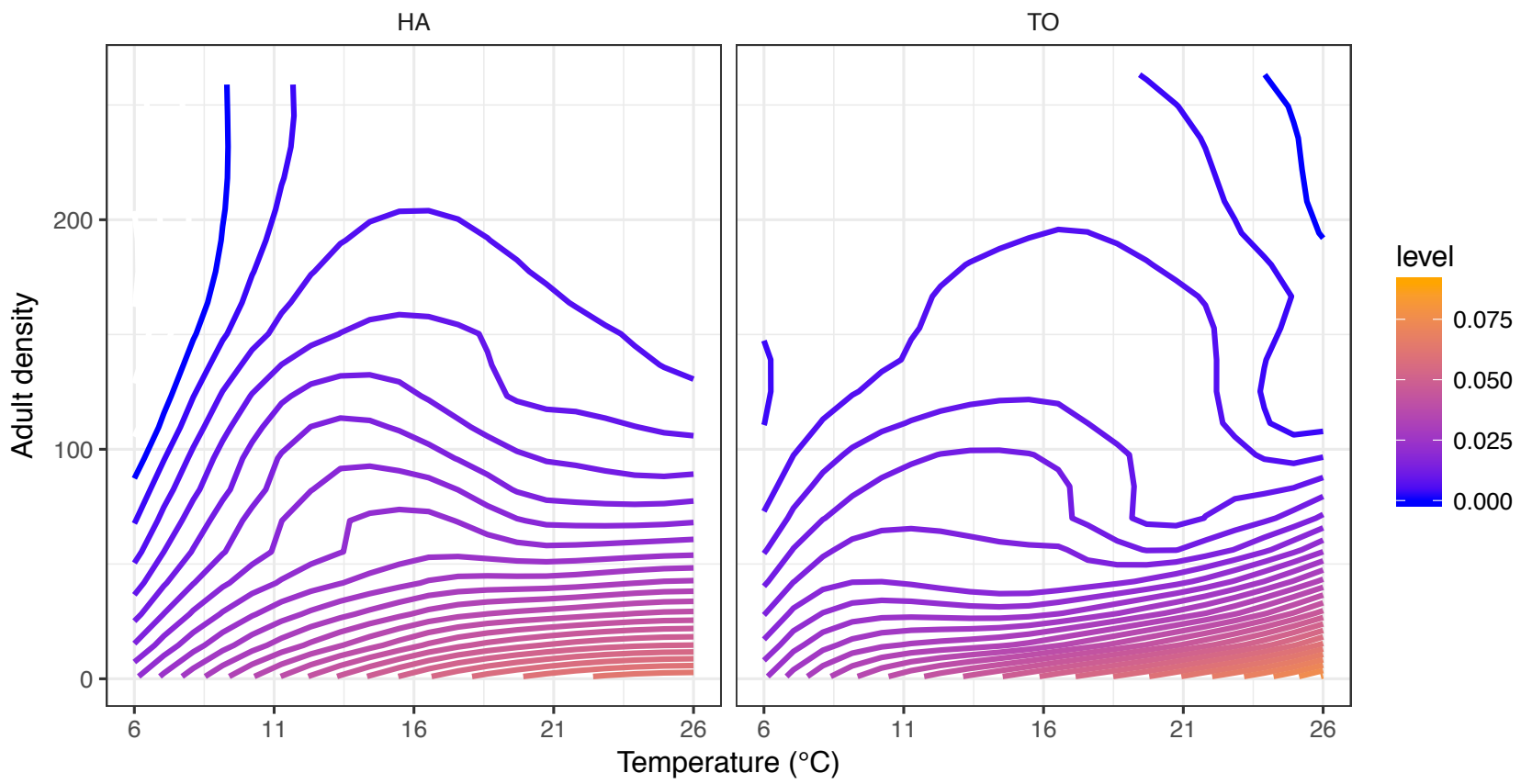

B Asymptotic length ( $\mathrm{mm})$

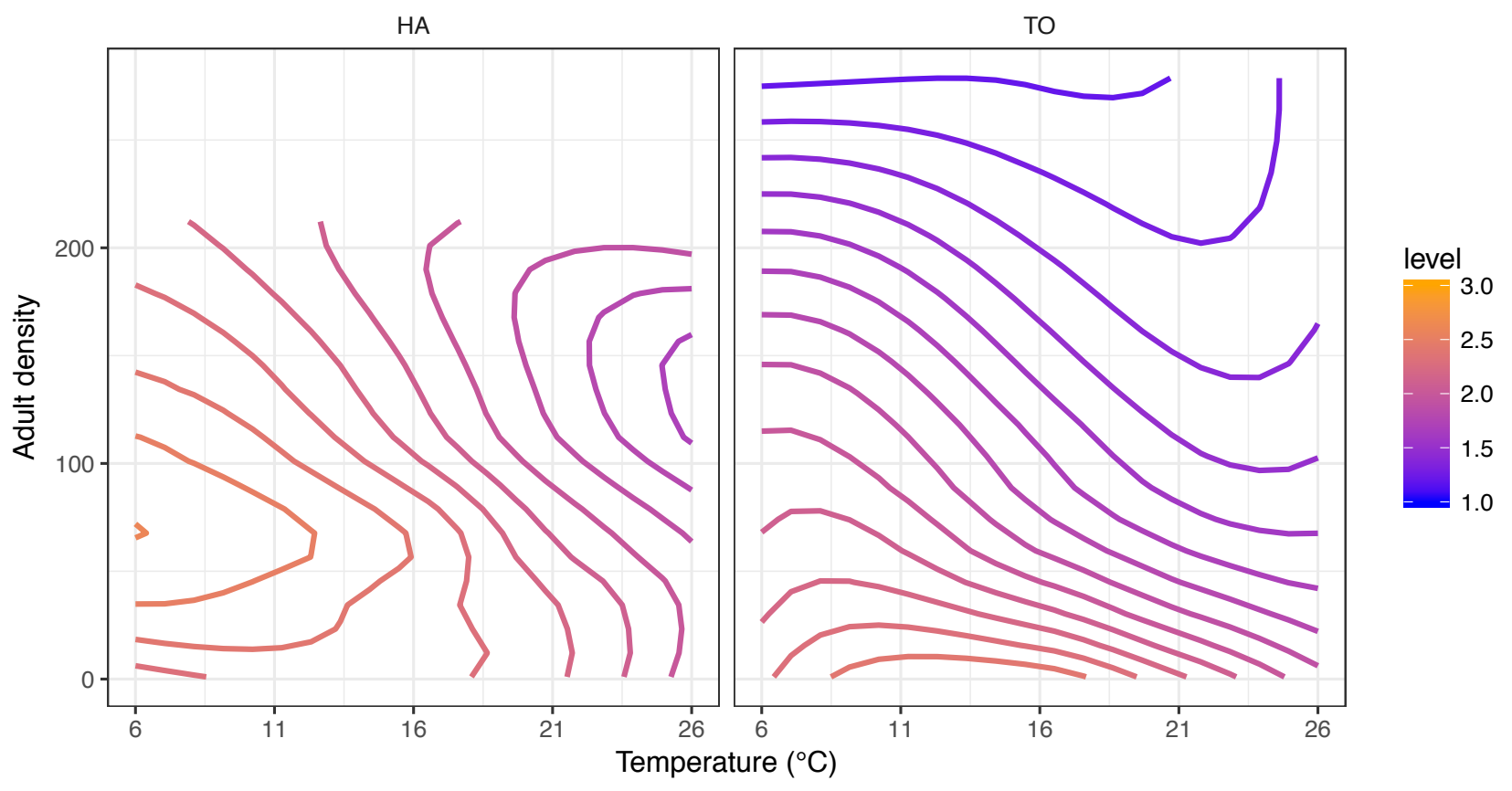


From individuals to populations: How intraspecific competition shapes thermal reaction norms

\section{Supporting tables}

Table S1: Best selected linear models describing the effect of adult density (log scale), temperature (as a factor) and lineage identity (HA and TO) on the growth rate (models A-C) and asymptotic body length (models D-F) measured in populations (Figure 4). Non-significant complex interactions that have been dropped from the initial full models are italicized. Effects and their interactions are tested with likelihood ratio tests using type 3 anova (Anova function from the car package). The main models $(A, D)$ are associated with sub-models $(B-C, E-F)$ for each of the two lineages.

\begin{tabular}{|c|c|c|c|}
\hline Factors & Likelihood ratio Chi-square & Df & $\mathrm{P}(>$ Chisq) \\
\hline \multicolumn{4}{|l|}{ (A) Growth rate in populations (HA \& TO) } \\
\hline Lineage (HA/TO) & 13.2 & 1 & $<0.001$ \\
\hline Temperature (factor) & 32.5 & 4 & $<0.001$ \\
\hline Adult density (log) & 26.1 & 1 & $<0.001$ \\
\hline Lineage ${ }^{\star}$ Temperature & 24.2 & 4 & $<0.001$ \\
\hline Lineage*Adult density (strength competition $\mathrm{HA}>\mathrm{TO}$ ) & 23.1 & 1 & $<0.001$ \\
\hline Temperature*Adult density & 12.1 & 4 & 0.017 \\
\hline Lineage ${ }^{\star}$ Temperature ${ }^{\star}$ Density & 2.4 & 4 & 0.66 \\
\hline \multicolumn{4}{|l|}{ (B) Growth rate in populations (HA) } \\
\hline Temperature (factor) & 80.1 & 4 & $<0.001$ \\
\hline Adult density (log) & 124.4 & 1 & $<0.001$ \\
\hline Temperature*Adult density & 9.2 & 4 & 0.057 \\
\hline Temperature (factor) $>6^{\circ} \mathrm{C}$ & 6.7 & 3 & 0.08 \\
\hline Adult density $(\log )>6^{\circ} \mathrm{C}$ & 123.8 & 1 & $<0.001$ \\
\hline Temperature*Adult density & 6.8 & 3 & 0.08 \\
\hline \multicolumn{4}{|l|}{ (C) Growth rate in populations (TO) } \\
\hline Temperature (factor) & 10.9 & 4 & 0.027 \\
\hline Adult density (log) & 37.6 & 1 & $<0.001$ \\
\hline Temperature ${ }^{\star}$ Adult density & 4.88 & 4 & 0.30 \\
\hline Temperature (factor) $>6^{\circ} \mathrm{C}$ & 5.8 & 3 & 0.12 \\
\hline Adult density $(\log )>6^{\circ} \mathrm{C}$ & 41.5 & 1 & $<0.001$ \\
\hline Temperature*Adult density & 3.3 & 3 & 0.35 \\
\hline \multicolumn{4}{|c|}{ (D) Asymptotic length in populations (HA \& TO) } \\
\hline Lineage $(\mathrm{HA}>\mathrm{TO})$ & 36.8 & 1 & $<0.001$ \\
\hline Temperature (factor) & 41.3 & 4 & $<0.001$ \\
\hline Adult density (log) & 0.01 & 1 & 0.95 \\
\hline Lineage ${ }^{\star}$ Temperature & 12.2 & 4 & 0.016 \\
\hline Temperature*Adult density & 70.3 & 4 & $<0.001$ \\
\hline Lineage*Adult Density & 0.4 & 1 & 0.5 \\
\hline Lineage ${ }^{*}$ Temperature ${ }^{\star}$ Density & 2.3 & 4 & 0.68 \\
\hline \multicolumn{4}{|l|}{ (E) Asymptotic length in populations (HA) } \\
\hline Temperature (factor) & 192.8 & 4 & $<0.001$ \\
\hline Adult density (log) & 52.1 & 1 & $<0.001$ \\
\hline Temperature ${ }^{\star} A d u l t$ density & 6.4 & 4 & 0.17 \\
\hline
\end{tabular}


From individuals to populations: How intraspecific competition shapes thermal reaction norms

\begin{tabular}{|c|c|c|c|}
\hline \multicolumn{4}{|c|}{ (F) Asymptotic length in populations (TO) } \\
\hline Temperature (factor) & 34.4 & 4 & $<0.001$ \\
\hline Adult density (log) & 0.02 & 1 & 0.88 \\
\hline Temperature*Adult density & 53.7 & 4 & $<0.001$ \\
\hline
\end{tabular}

Table S2: Model including the adult biosurface (sum of the surface of adults in populations) as a covariable rather than number of adults to explain the observed variations of cohort growth rates. When the total surface of adults (biosurface) is taken into account rather than their number, the previously observed difference between the two lineages (significant interaction between lineage and density in model $A$ in Table 3 suggesting that the strength of competition in higher for HA) vanishes. This shows that the strength of competition is the same between the two lineages when controlling for adult size.

\begin{tabular}{|c|c|c|c|}
\hline Factors & $\begin{array}{l}\text { Likelihood ratio } \\
\text { Chi-square }\end{array}$ & Df & P (>Chisq) \\
\hline \multicolumn{4}{|l|}{ Growth rate in populations (HA \& TO) } \\
\hline Lineage (HA/TO) & 2.2 & 1 & 0.14 \\
\hline Temperature (factor) & 38.0 & 4 & $<0.001$ \\
\hline Adult Biosurface (mm2) & 6.1 & 1 & 0.013 \\
\hline Lineage*Temperature & 19.6 & 4 & $<0.001$ \\
\hline Temperature*Biosurface & 17.5 & 1 & 0.0015 \\
\hline Lineage*Biosurface & 0.67 & 1 & 0.41 \\
\hline Lineage ${ }^{*}$ Temperature* Biosurface & 2.0 & 4 & 0.73 \\
\hline
\end{tabular}

Table S3: This table gathers the estimates (mean and 95\% confidence interval in brackets) of the parameters of models $\mathrm{A}$ (growth rate) and B (asymptotic body length) from Table 1. The predicted asymptotic body length of the clone HA in the population raised at $6^{\circ} \mathrm{C}$ is $2.54 \mathrm{~mm}$. At $21^{\circ} \mathrm{C}$, the predicted asymptotic size of isolated TO is $2.3 \mathrm{~mm}$ (2.54-0.89-0.46-0.37+0.43+1.03+0.64-0.62=2.3).

\begin{tabular}{|l|l|l|}
\hline & Growth rate $(\mu \mathrm{m} /$ day) & Asymptotic body length $(\mathrm{mm})$ \\
\hline Intercept $\left(6^{\circ}, \mathrm{HA}\right.$, population $)$ & $8[2.7 ; 13.3]$ & $2.54[2.31 ; 2.76]$ \\
\hline $11^{\circ}$ & $1.9[-4.9 ; 8.7]$ & $-0.19[-0.47 ; 0.09]$ \\
\hline $16^{\circ}$ & $3.7[-3.7 ; 11.2]$ & $-0.44[-0.75 ;-0.14]$ \\
\hline $21^{\circ}$ & $3.8[-1.8 ; 9.4]$ & $-0.89[-1.13 ;-0.66]$ \\
\hline $26^{\circ}$ & $13.2[7.1 ; 19.2]$ & $-0.62[-0.88 ;-0.37]$ \\
\hline TO & $5.6[-1.6 ; 12.8]$ & $-0.46[-0.75 ;-0.16]$ \\
\hline Isolated individual & $15.7[5.2 ; 26.3]$ & $-0.37[-0.79 ; 0.05]$ \\
\hline TO $11^{\circ}$ & $-8.6[-18 ; 0.9]$ & $-0.1[-0.48 ; 0.28]$ \\
\hline TO 16 & $-10[-20.1 ; 0]$ & $-0.07[-0.47 ; 0.33]$ \\
\hline TO 21 & $-6[-13.7 ; 1.7]$ & $0.43[0.12 ; 0.74]$ \\
\hline TO 26 & $-11.4[-20.2 ;-2.6]$ & $0.21[-0.14 ; 0.57]$ \\
\hline Isolated individual $11^{\circ}$ & $10.9[-1.9 ; 23.7]$ & $0.32[-0.18 ; 0.83]$ \\
\hline Isolated individual $16^{\circ}$ & $24.6[11.5 ; 37.8]$ & $0.61[0.09 ; 1.13]$ \\
\hline Isolated individual $21^{\circ}$ & $38.1[25.6 ; 50.7]$ & $1.03[0.54 ; 1.53]$ \\
\hline Isolated individual 26 & $27.7[15.3 ; 40.1]$ & $0.35[-0.14 ; 0.84]$ \\
\hline TO Isolated & $-5.6[-18.3 ; 7]$ & $0.64[0.14 ; 1.14]$ \\
\hline TO Isolated individual $11^{\circ}$ & $14.5[-1.9 ; 31]$ & $0.12[-0.53 ; 0.77]$ \\
\hline TO Isolated individual $16^{\circ}$ & $9.1[-7.1 ; 25.3]$ & $0.01[-0.63 ; 0.65]$ \\
\hline TO Isolated individual $21^{\circ}$ & $11.8[-5.3 ; 28.9]$ & $-0.62[-1.29 ; 0.05]$ \\
\hline TO Isolated individual $26^{\circ}$ & $29[13,5 ; 44,6]$ & $-0.4[-1,02 ; 0,21]$ \\
\hline
\end{tabular}




\section{References}

Abramoff, M. D., Magalhaes, P. J., \& Ram, S. J. (2004). Image processing with ImageJ. Biophotonics international, 11(7), 36-42.

Amarasekare, P., \& Coutinho, R. M. (2014). Effects of temperature on intraspecific competition in ectotherms. The American Naturalist, 184(3), E50-E65.

Angilletta, M. (2009). Thermal adaptation : a theoretical and empirical synthesis. Oxford; New York: Oxford University Press.

Atkinson, D. (1994). Temperature and organism size-A biological law for ectotherms? Advances in Ecological Research, 25, 1-58.

Atkinson, D. (1996). Ectotherm life-history responses to developmental temperature. In I. A. Johnston \& A. F. Bennett (Eds.), Animals and Temperature. Phenotypic and Evolutionary Adaptation (pp. 183-204). Cambridge: Cambridge University Press.

Bassar, R. D., Letcher, B. H., Nislow, K. H., \& Whiteley, A. R. (2016). Changes in seasonal climate outpace compensatory density-dependence in eastern brook trout. Global Change Biology, 22(2), 577-593.

Birkemoe, T., \& Leinaas, H. P. (2000). Effects of temperature on the development of an arctic Collembola $(\mathrm{Hy}-$ pogastrura tullbergi). Functional Ecology, 14(6), 693-700.

Brown, J. H., Gillooly, J. F., Allen, A. P., Savage, V. M., \& West, G. B. (2004). Toward a metabolic theory of ecology. Ecology, 85(7), 1771-1789.

Daufresne, M., Lengfellner, K., \& Sommer, U. (2009). Global warming benefits the small in aquatic ecosystems. Proceedings of the National Academy of Sciences, 106(31), 12788-12793.

De Jong, G., \& van Noordwijk, A. J. (1992). Acquisition and allocation of resources: genetic (co)variances, selection, and life histories. The American Naturalist, 139(4), 749-770.

DeLong, J. P. (2012). Experimental demonstration of a 'rate-size' trade-off governing body size optimization. Evolutionary Ecology Research, 14(3), 343-352.

Driessen, G., Ellers, J., \& Van Straalen, N. M. (2007). Variation, selection and heritability of thermal reaction norms for juvenile growth in Orchesella cincta (Collembola : Entomobryidae). European Journal of Entomology, 104(1), 39-46.

Edeline, E., Lacroix, G., Delire, C., Poulet, N., \& Legendre, S. (2013). Ecological emergence of thermal clines in body size. Global Change Biology, 19(10), 3062-3068.

Ellers, J., \& Driessen, G. (2011). Genetic correlation between temperature-induced plasticity of life-history traits in a soil arthropod. Evolutionary Ecology, 25(2), 473-484.
Ellers, J., Mariën, J., Driessen, G., \& van Straalen, N. M. (2008). Temperature-induced gene expression associated with different thermal reaction norms for growth rate. Journal of Experimental Zoology Part B Molecular and Developmental Evolution, 310(2), 137-147.

Fountain, M. T., \& Hopkin, S. P. (2005). Folsomia candida (Collembola): a "standard" soil arthropod. Annual Review of Entomology, 50, 201-222.

Gardner, J. L., Peters, A., Kearney, M. R., Joseph, L., \& Heinsohn, R. (2011). Declining body size: a third universal response to warming? Trends in Ecology and Evolution, 26(6), 285-291.

Gherardi, F., Coignet, A., Souty-Grosset, C., Spigoli, D., \& Aquiloni, L. (2013). Climate warming and the agonistic behaviour of invasive crayfishes in Europe. Freshwater Biology, 58(9), 1958-1967.

Ghosh, S. M., Testa, N. D., \& Shingleton, A. W. (2013). Temperature-size rule is mediated by thermal plasticity of critical size in Drosophila melanogaster. Proceedings of the Royal Society B Biological Sciences, 280(1760), 20130174.

Gillooly, J. F., Brown, J. H., West, G. B., Savage, V. M., \& Charnov, E. L. (2001). Effects of size and temperature on metabolic rate. Science, 293, 2248-2251.

Gilman, S. E., Urban, M. C., Tewksbury, J., Gilchrist, G. W., \& Holt, R. D. (2010). A framework for community interactions under climate change. Trends in Ecology and Evolution, 25(6), 325-331.

Hoefnagel, K. N., \& Verberk, W. C. E. P. (2015). Is the temperature-size rule mediated by oxygen in aquatic ectotherms? Journal of Thermal Biology, 54, 56-65.

Hoefnagel, K. N., de Vries, E. H. J. L., Jongejans, E., \& Verberk, W. C. E. P. (2018). The temperature-size rule in Daphnia magna across different genetic lines and ontogenetic stages: Multiple patterns and mechanisms. Ecology and Evolution, 8, 3828-3841.

Horne, C. R., Hirst, A. G., \& Atkinson, D. (2015). Temperature-size responses match latitudinal-size clines in arthropods, revealing critical differences between aquatic and terrestrial species. Ecology Letters, 18(4), 327-335.

Ihaka, R., \& Gentleman, R. (1996). R: A Language for Data Analysis and Graphics. Journal of Computational and Graphical Statistics 5: 299. doi: 10.2307/1390807.

Johnson, C. A., Coutinho, R. M., Berlin, E., Dolphin, K. E., Heyer, J., Kim, B. et al. (2015). Effects of temperature and resource variation on insect population dynamics: the bordered plant bug as a case study. Functional Ecology, 30(7), 1122-1131.

Karan, D., Morin, J. P., Moreteau, B., \& David, J. R. (1998). Body size and developmental temperature in 
Drosophila melanogaster: analysis of body weight reaction norm. Journal of Thermal Biology, 23(5), 301-309.

Kingsolver, J. G., \& Woods, H. A. (1997). Thermal sensitivity of growth and feeding in Manduca sexta caterpillars. Physiological Zoology, 70(6), 631-638.

Kingsolver, J. G. (2009). The well-temperatured biologist. (American Society of Naturalists Presidential Address). The American Naturalist, 174(6), 755-768.

Le Bourlot, V. (2014). Compétition par interférence, température et dynamique des populations structurées: étude expérimentale et théorique chez le Collembole Folsomia candida. Paris 6, Paris.

Le Bourlot, V., Mallard, F., Claessen, D., \& Tully, T. (2015). A simple graphical method for displaying structured population dynamics and STdiag, its implementation in an R package. Soil Organisms, 87(3), 203-213.

Le Bourlot, V., Tully, T., \& Claessen, D. (2014). Interference versus exploitative competition in the regulation of size-structured populations. The American Naturalist, 184(5), 609-623.

Liefting, M., Hoffmann, A. A., \& Ellers, J. (2009). Plasticity versus environmental canalization: population differences in thermal responses along a latitudinal gradient in Drosophila serrata. Evolution, 63(8), 1954-1963.

Mallard, F., Farina, M., \& Tully, T. (2015). Within species variation in long-term trajectories of growth, fecundity and mortality in the Collembola Folsomia candida. Journal of Evolutionary Biology, Epub, 1-9.

Ohlberger, J., Edeline, E., Vøllestad, L. A., Stenseth, N. C., \& Claessen, D. (2011). Temperature-driven regime shifts in the dynamics of size-structured populations. The American Naturalist, 177(2), 211-223.

Park, T. (1954). Experimental studies of interspecies competition II. Temperature, humidity, and competition in two species of Tribolium. Physiological Zoology, 27(3), 177-238.

Persson, L., De Roos, A. M., Claessen, D., Byström, P., Lövgren, J., Sjögren, S. et al. (2003). Gigantic cannibals driving a whole-lake trophic cascade. Proceedings of the National Academy of Sciences, 100(7), 4035-4039.

Savage, V. M., Gillooly, J. F., Brown, J. H., West, G. B., \& Charnov, E. L. (2004). Effects of body size and temperature on population growth. The American Naturalist, 163(3), 429-441.

Sebens, K. P. (1987). The ecology of indeterminate growth in animals. Annual Review of Ecology and Systematics, 18, 371-407.

Stam, E. M., de Leemkule, M. A. V., \& Ernsting, G. (1996). Trade-offs in the life history and energy budget of the parthenogenetic Collembolan Folsomia candida (Willem). Oecologia, 107(3), 283-292.

Tully, T. (2019). From individuals to populations: How intraspecific competition shapes thermal reaction norms. Dryad, Dataset.

Tilman, D., Mattson, M., \& Langer, S. (1981). Competition and nutrient kinetics along a temperature gradient: an experimental test of a mechanistic approach to niche theory. Limnology and Oceanography, 26(6), 1020-1033.

Tufte, E. R. (2001). The visual display of quantitative information (2nd ed.). Cheshire, Connecticut: Graphics Press.

Tully, T., D’Haese, C. A., Richard, M., \& Ferriere, R. (2006). Two major evolutionary lineages revealed by molecular phylogeny in the parthenogenetic collembola species Folsomia candida. Pedobiologia, 50(2), 95-104.

Tully, T., \& Ferrière, R. (2008). Reproductive flexibility: genetic variation, genetic costs and long-term evolution in a Collembola. PLoS One, 3(9), e3207.

Tully, T., \& Lambert, A. (2011). The evolution of postreproductive life span as an insurance against indeterminacy. Evolution, 65(10), 3013-3020.

van Dooren, T. J. M., Tully, T., \& Ferrière, R. (2005). The analysis of reaction norms for age and size at maturity using maturation rate. Evolution, 59(3), 500-506.

Vasseur, D., \& McCann, K. (2005). A Mechanistic Approach for Modeling Temperature-Dependent Consumer-Resource Dynamics. The American Naturalist, 166(2), 184-198.

Walczyńska, A., Kiełbasa, A., \& Sobczyk, M. (2016). 'Optimal thermal range' in ectotherms: Defining criteria for tests of the temperature-size-rule. Journal of Thermal Biology, 60, 41-48.

Walters, R. J., \& Hassall, M. (2006). The temperaturesize rule in ectotherms: may a general explanation exist after all? The American Naturalist, 167(4), 510-523.

Wickham, H. (2009). ggplot2: Elegant Graphics for Data Analysis. New York: Springer-Verlag.

Willem, V. (1902). Note préliminaire sur les Collemboles des Grottes de Han et de Rochefort. Annales de la Société Entomologique de Belgique, 46, 275-283.

Zuo, W., Moses, M. E., West, G. B., Hou, C., \& Brown, J. H. (2011). A general model for effects of temperature on ectotherm ontogenetic growth and development. Proceedings of the Royal Society B: Biological Sciences, 279(1734), 1840-1846. 